\title{
Apparel Manufacturing Glossary for Application Protocol Development
}

Michael E. Read

U.S. DEPARTMENT OF COMMERCE Technology Administration National Institute of Standards and Technology

Manufacturing Engineering Laboratory Manufacturing Systems Integration Division Gaithersburg, MD 20899

Sponsored in part by

DLA Manufacturing Technology Program

QC 



\section{Apparel Manufacturing Glossary for Application Protocol Development}

Michael E. Read

U.S. DEPARTMENT OF COMMERCE Technology Administration National Institute of Standards and Technology

Manufacturing Engineering Laboratory Manufacturing Systems Integration Division Gaithersburg, MD 20899

Sponsored in part by

DLA Manufacturing Technology Program

February 1995

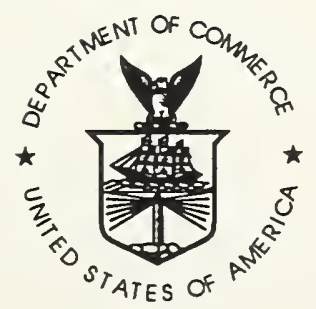

U.S. DEPARTMENT OF COMMERCE Ronald H. Brown, Secretary

TECHNOLOGY ADMINISTRATION Mary L. Good, Under Secretary for Technology

NATIONAL INSTITUTE OF STANDARDS AND TECHNOLOGY

Arati Prabhakar, Director 


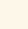




\section{PREFACE}

The National Institute of Standards and Technology (NIST) is engaged in a project to develop product data standards to support computer integration of the apparel product life cycle. The project is sponsored by the Defense Logistics Agency (DLA), and has been named the Apparel Product Data Exchange Standard (APDES) project.

The APDES project utilizes the techniques being used by and developed for the Standard for the Exchange of Product Model Data (STEP). STEP is an emerging international standard for representing the physical and functional characteristics of a product throughout the product's life cycle. Formal standards for STEP are being published under the auspices of the International Organization for Standardization (ISO) in the document series 10303-X. Many of the information requirements, as well as the software tools being developed to support STEP, are applicable for any manufacturing industry. To serve the needs for a particular industry, application protocols (APs) are developed to designate the specific information and application requirements for that industry. The APs draw upon integrated resources, basic STEP entities, to share the same information among different APs. As a standard, STEP will permit communications among computer environments, each of which performs various product life cycle functions. An advantage of STEP is that it will support the integration of the computer environments using a shared database. 


\section{Disclaimer}

Certain commercial equipment, instruments, materials, organizations, or companies, are identified in this paper in order to facilitate understanding. Such identification does not imply recommendation or endorsement by the National Institute of Standards and Technology (NIST), nor does it imply that the materials or equipment identified are necessarily the best available for the purpose. 


\section{TABLE OF CONTENTS}

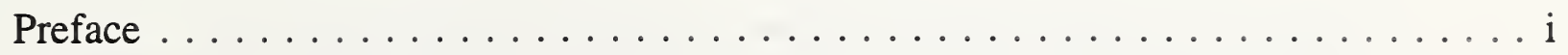

1. Introduction $\ldots \ldots \ldots \ldots \ldots \ldots \ldots \ldots \ldots \ldots \ldots \ldots \ldots \ldots \ldots$

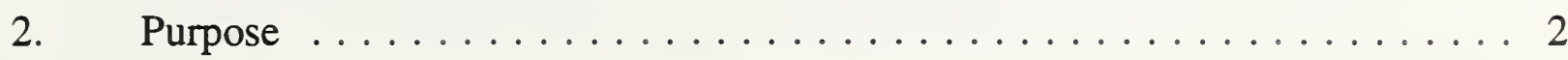

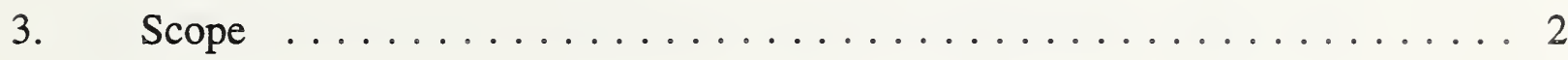

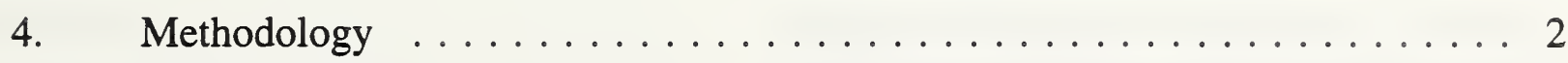

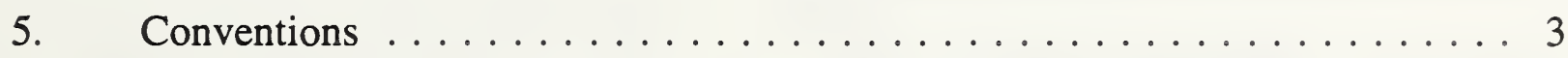

6. Future Plans ........................... 3

7. Acknowledgments $\ldots \ldots \ldots \ldots \ldots \ldots \ldots \ldots \ldots$

8. References to the Introduction $\ldots \ldots \ldots \ldots \ldots \ldots \ldots$

Glossary A-Z . ........................ 5

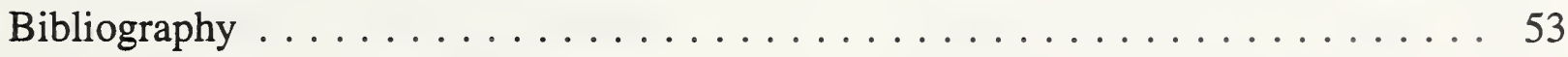




\title{
APPAREL MANUFACTURING GLOSSARY FOR APPLICATION PROTOCOL DEVELOPMENT
}

\author{
Michael E. Read \\ Manufacturing Systems Integration Division \\ Manufacturing Engineering Laboratory \\ National Institute of Standards and Technology
}

\begin{abstract}
A glossary of terms used in apparel manufacturing, specifically those used in the pattern-making process, are listed verbatim from six primary sources. These terms are needed in the development of new, ISO Standard for the Exchange of Product Model Data (STEP), application protocols for the apparel industry. The purpose of this report is to present to the apparel industry a working set of terms and meanings from the published literature, and to act as a catalyst in the development of a set of consensus terms and meanings.
\end{abstract}

KEY WORDS: AP; APDES; apparel; application protocol; glossary; pattern making; STEP.

\section{Introduction}

The Apparel Product Data Exchange Standard (APDES) project is part of a substantial program sponsored by the Defense Logistics Agency (DLA) to improve apparel manufacturing technology. The DLA program is advancing technology from traditional, size-based, "ready-to-wear" methods to "made-to-measure" methods that use body measurement data directly. Additionally, the program is advancing production methods from fixed procedures based on standard products to flexible, computer-integrated manufacturing using product representation standards to communicate requirements. These newly developed technologies are expected to lead to better apparel fit, higher product quality, more economic unit production, and quicker response to market demands. All told, the program is a broad evolution toward integrated enterprises, in which all phases of a product's life cycle are coordinated through a framework of standards, concurrent engineering practices, and supporting technologies.

The goal for the APDES project is to develop manufacturing data standards based on the Standard for the Exchange of Product Model Data (STEP) that can enable integration of the functions in an apparel manufacturing enterprise. Thus far, accomplishments in the APDES project include:

- a computer program that translates apparel pattern data between two proprietary industry file formats using a set of neutral data structures based on the NIST apparel information model $[1,2]$;

- $\quad$ a prototype application protocol ${ }^{1}$ for ready-to-wear pattern making[3]; and

\footnotetext{
I A part of the ISO/STEP standards, ISO 10303-x series, that describes the use of integrated resources satifying the scope and information requirements for a specific application context. [ISO-1;p.2]
} 
a report that proposes a set of manufacturing data interfaces for integrating an apparel manufacturing enterprise[4].

After the APDES project began, it became apparent that a glossary of apparel manufacturing terms would be a useful resource to develop and maintain.

The complexity and diversity of the apparel industry has been recognized by many experts in the field. One has said that "each segment of the trade has had its own history during which time specialized methods and equipment have led to trade jargon peculiar to that segment alone[5]."

Another has stated that "researchers have found that trade sources often identify different stitches, finishes, and construction applications by the same name, and that terms well known in one segment of the industry are not always familiar in others[6]."

Occasionally the same term may have different meanings, especially in different segments of the industry. Conversely, different terms may have the same meaning.

Standards development requires that all terms used in a standard have a clearly defined meaning. This glossary represents the first step in achieving a consensus of meaning for the terms used in developing apparel manufacturing standards.

\section{Purpose}

Most standards publications and specifications published by standards organizations (e.g., ASTM, ANSI, ISO) ${ }^{2}$ have a glossary section where key terms are defined. In the development of new standards, this is a necessity.

This glossary was created with three purposes in mind:

(1) to illustrate and compare the definitions that were found in the published literature;

(2) to serve as a strawman to produce one set of consensus terms with unambiguous definitions for the apparel industry; and

(3) to be used as a resource for the APDES/STEP application protocol (AP) development.

This glossary shows the variety of meanings attributed to given terms, lists synonyms, and shows different terms which have the same meaning. It will be an aid to standards developers as a mechanism to clarify the terminology used in apparel standards related to pattern-making.

\section{Scope}

The scope of this initial version of the glossary is to include terms in the patternmaking process and areas that directly influence or affect that process.

In addition, due to the need to develop several STEP APs to encompass the entire apparel industry, we have included some broad context terms of general use to the entire industry, as well as some very specific terms and acronyms relevant to the STEP AP process, itself.

\footnotetext{
${ }^{2}$ ASTM is the American Society for Testing and Materials; ANSI is the American National Standards Institute; and ISO is the International Organization for Standardization.
} 


\section{Methodology}

Debbie Gioello's Fashion Production Terms, FPTS, was selected as the starting point for the initial identification of terms to be included. The chapters in her book are organized around the flow of the production process, or the route of the garment, from its origin through development to completion. The terms she presented were grouped according to the subject in which they may be used or applied. This made it convenient to focus on terms relevant to our scope.

The other primary reference books, AMFG, AMHB, CLEM, FDF, and GTAM ${ }^{3}$, were then scanned to extract definitions for the terms found in FPTS, as well to add additional relevant terms as found.

Relevant terms were also selected from the specialized publications, GIT2 and KOPP.

For some special meanings, WEB1 was selected to add comprehensiveness to some terms.

\section{Conventions}

Each entry in the glossary is composed of a term and a definition section. Terms consist of one or more words, shown in "boldface." The definitions follow and, if more than one, are numbered sequentially. After each definition, the source is shown by a reference abbreviation and page number in brackets. The abbreviations for the cited publications are listed separately, in the Bibliography section, at the end of the glossary.

${ }^{3}$ Capitalized, alpha/numeric references codes shown, e.g. AMFG, are fully explained and noted in the Bibliography section, at the rear of this report.
Definitions are quoted exactly as found in the literature, without modification. If two definitions are similar, but from different references, each is listed separately and numbered separately. If two definitions from different references are identical, then the reference abbreviations are shown together, in one set of brackets, separated by a semicolon.

Additionally, the following procedures and formatting rules are used:

acronyms -

listed as two entries, except as under "3)":

1) alphabetically under the acronym, with the spelled out meaning of the acronym following; 2) under the spelled-out word order of the acronym, followed by a definition of the acronym and a reference to it, if available.

3) where the spelled-out acronym and the acronym, itself, are adjacent entries, then only one entry is listed, with the acronym as the leading term.

- "..." (ellipsis) and italicized words, or phrases -

- when the entry word needs to be repeated in the context of a phrase, the ellipsis, "...", is used to denote the omission of the entry term, and the italics are used with the adjoining context words.

- in reference to a related word, the phase, "also see ..." or "see ...", in italics, is used.

pronunciation guide -

with some difficult to pronounce words, i.e. some of the French words, a standard phonetic spelling is shown in parentheses following the word to aid the reader; for example:

$$
\text { prêt-à-porter (pret-ah-por-tay) }
$$

\section{Future Plans}

To make this glossary a valuable resource for standards development, experts and users in the apparel industry are encouraged to help clarify terms and definitions. We 
would like to get input and advice from industry in forming a consensus on the terms and meanings so as to minimize conflicting definitions and improper use.

Help from experts in the field with other words, terms, and definitions which we may have overlooked, is also encouraged. Especially needed are trade terms and definitions that are not in the published literature, but are used in the real world of apparel production and manufacturing.

Interest has been expressed to make this glossary available on the Clemson Apparel bulletin board, known as AMIS, and this possibility will be pursued. Perhaps this will provide an easy way to obtain user feedback on existing terms and definitions, as well as to provide input for additional terms and definitions.

Later, "classification" information, that is the systematic arrangement into groups or categories of these words, may be added.

Additionally, APDES personnel will continue to be actively involved in Apparel organizations, like the American Apparel Manufacturers Association, to become aware of the current problems facing the industry, and to offer solutions to the challenges in modernizing their operations to become more productive and efficient.

\section{Acknowledgments}

I would like to thank Laura Atkinson, who was involved initially in this project, and especially Tina Lee, Howard Moncarz, Dr. Theodore Hopp, and Jeane Ford, who were all very helpful with their ideas, proofing, editorial comments, and encouragement in assisting me with completing this glossary. Especially important was Dr. Hopp's programming assistance with a complex merge of database files into camera-ready formatted text files.

I also would like to thank Dr. Grace Kunz of Iowa State University for donation of her apparel book, Apparel Manufacturing, AMFG, which was used as a valuable source of information.

\section{References to the Introduction}

[1] Lee, Y.T., "On Extending the Standard for the Exchange of Product Data to Represent Two-Dimensional Apparel Pattern Pieces," NISTIR-4358; June, 1990; 22 pp.

[2] Moncarz, H.T. and Lee, Y.T., "Apparel STEP Translator," NISTIR-4612; June, 1991; 14 pp.

[3] Lee, Y.T. and Moncarz, H.T., "A Prototype Application Protocol for Ready-toWear Pattern Making," NISTIR-5115; Jan., 1993; 27 pp.

[4] Moncarz, H.T. and Lee, Y.T., "Report on scoping the Apparel Manufacturing Enterprise," NISTIR-5106; Jan., 1993; $28 \mathrm{pp}$.

[5] Walfish, J. in Foreword to Fashion Production Terms, by D. A. Gioello and B. Berke (Fairchild Pub., New York, 1979); p. vii.

[6] Gioello, D.A. in Preface to Fashion Production Terms, by D. A. Gioello and B. Berke (Fairchild Pub., New York, 1979); p. ix. 


\section{Apparel Manufacturing Glossary for Application Protocol Development}

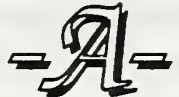

AAM

Application Activity Model

\section{accessories}

1. Items that enhance the aesthetic appeal or function of a garment: belts, scarves, bows, pins, etc. [AMFG; p. 513]

2. Similar to "notions" and "findings," which see, but these items are of specialized use. [FPTS; p. 139]

see also "trim"

\section{ADS}

Apparel Design System

\section{AIM}

Application Interpreted Model

\section{allowance}

1. In the individual incentive system, a percentage of time added to the cycle to cover personal fatigue and delay. [CLEM; p. 1]

2. ... for movement ease; Refers to situations where the pattern section must be diminished because of the elasticity or elongation characteristic of the fabric grain structure used when the pattern is cut. [AMHB; p. 83]

\section{AMA \\ Apparel Manufacturing Architecture \\ anthropometry \\ 1. Body-size studies which become the "stan- dard" by which fitting forms and sizes are based. [GTAM; p. 117] \\ 2. The study of human body measurements, especially on a comparative basis. [WEB1; p. 49]}

AP

Application Protocol

\section{APDES}

Apparel Product Data Exchange Standard

apex

1. The bust line. [AMHB; p. 61]

2. The point at which a dart tapers to an end. [FDF; p. 11]; [FPTS; p. 31]

3. Highest point of the bust on model form; used as a guide when establishing crossgrain position on front bodice muslin. [FPTS; p. 38]

\section{apparel}

1. Any type of clothing worn by men, women, and children. Synonyms: attire, clothes, costume, dress, garb, garment, habit, uniform, robe, raiment, and vestment. [FDF; p. 11]

2. Term used since early 14 th century to denote clothing, particularly a suit of clothes. [FDF; p. 11]

\section{apparel design}

Basically an activity in applied geometrics with use of color to highlight the effect. [AMHB; p. 54]

\section{apparel design feature}

Style lines and/or design features with the silhouette of the garment, including necklines, collars, pockets, closures, trimmings, yokes, and/or sleeves. [FPTS; p. 2]

\section{apparel design system (ADS)}

Computer software applied to the garment design process. [AMFG; p. 513]

\section{apparel industry}

The manufacturers, jobbers, and contractors engaged in the manufacture of ready-to-wear clothing for men, women, and children. Also called "cuttingup trade," "garment trade," "needle trade," and "rag business." [FDF; p. 11] 


\section{apparel manufacturing architecture (AMA)}

A "to be" framework that represents an apparel manufacturing enterprise of the future developed by S. Jayaraman and R. Malhotra of Georgia Tech. [GIT2]

\section{Apparel Product Data Exchange Standard (APDES)}

A project at NIST that coordinates and develops apparel product data specifications for supporting computer integration of the apparel product life cycle.

\section{apparel silhouette}

1. Refers to the geometric perimeter of the product. [AMHB; p. 54]

2. Shape or outline of a garment, not including design detail, identified as "Form Fitted to Full," which includes Sheath, Shift, A-line, and Tent styles; "Horizontal Division - Seams," which includes Empire (under bustline), Fit-and-Flare (natural waistline), and Long Torso (hipline); and "Horizontal Division Overlays," which includes Tunic and Tiers. [FPTS; p. 2]

\section{application activity model (AAM)}

A STEP-defined model that describes an application in terms of its processes and information flows. [ISO-1; p. 2]

\section{application interpreted model (AIM)}

A STEP-defined information model that uses the integrated resources necessary to satisfy the information requirements and constraints of an application reference model, within an application protocol. [ISO-1; p. 2]

\section{application protocol (AP)}

A part of the ISO/STEP standards, ISO 10303-x series, that describes the use of integrated resources satisfying the scope and information requirements for a specific application context.

[ISO-1; p. 2]

\section{application reference model (ARM)}

A STEP information model that describes the information requirements and constraints of a specific application. [ISO-1; p. 2]

\section{appliqué}

1. Emblems, cut fabric shapes, figures, or motifs that are superimposed and sewn or fused to garment components. [AMFG; p. 513]

2. Added feature of garment, usually drawn full-scale, separately by the designer, and accompanied by specifications for thread color and type, as well as size and number of stitches. [GTAM; p. 93]

3. Surface pattern made by cutting out fabric or lace designs and attaching them to another fabric or lace by means of embroidery or stitching. [FDF; p. 11]

4. (n.) A cutout decoration fastened to a larger piece of material. [WEB 1; p. 55]

5. (v.) To apply (as a decoration or ornament) to a larger surface: overlay. [WEB $1 ;$ p. 55]

\section{ARM}

Application Reference Model 


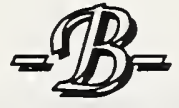

\section{backstitch (also spelled "back-stitch")}

1. A stitch which will show on the back side of a part, but not on the top. [CLEM; p. 2]

2. Sewing term for reversing stitch on sewing machine. Used to secure threads at the beginning and ending of seams. Also called "staying a seam" or "stay." [FDF; p. 21]

3. A common trade name for stitch-type 202 , where adjacent stitches share the same needle hole. [AMHB; p. 174]

\section{back-tack(s)}

Formed by superimposing three (or more) equal lengths of stitch chains on top of one another. [AMHB; p. 293]

\section{balance}

One of the standards of fit, and is the relationship of the different parts of a garment to each other, including the way in which they drape or hang from the body of the wearer. To appear "balanced," a garment or part must fall or extend away from the body the same distance front-to-back and side-to-side. [GTAM; p. 120]

\section{balancing}

1. Process of matching two seams to establish grainline, seam length, and amount of flare or fullness introduced. [KOPP; p. 3]

2. ... of muslin; The matching of grains on adjacent pattern sections. [FPTS; p. 38]

3. ... patternmaking lines; The process of matching or establishing grainlines and/or a common seam line on adjacent pattern pieces. [FPTS; p. 31]

\section{basic block}

see "block, basic"

\section{basics}

Products with little demand for change in style because of fashion. [AMFG; p. 513]

\section{baste}

1. To sew the edges of two plies of fabric together flat with long, loose stitches until they can be sewn firmly together by machine. [CLEM; p. 3]

2. To stitch fabrics together either by hand or with large machine stitches to hold in place prior to sewing final seams. After stitching, bastings are removed. [FDF; p. 28]

\section{basting}

1. A means of temporarily holding together two or more plies of fabric or trimming during various phases of garment construction. It is used as a guide for sewing and to hold a garment together for fitting before the final hand or machine stitching. [FPTS; p. 160]

2. A large temporary stitch. [GTAM; p. 58]

\section{basting, diagonal}

An even or uneven stitch taken at an angle to the direction of the grain or seam, producing a pattern of parallel slanting lines. Also called "tailor basting." [FPTS; p. 161]

\section{basting, even}

A series of hand stitches where the length and spacing of the stitch are each 0.25 inch $(6.4 \mathrm{~mm})$. Worked so that the stitches are easily removed after permanent stitching. [FPTS; p. 161]

\section{basting, machine}

The joining of garment sections using an easily removable chainstitch or a row of single needle lockstitches sewn with decreased thread tension and increased stitch length. [FPTS; p. 161]

\section{basting, pin}

A process of joining seams or garment sections by pinning. Pins are placed perpendicular to the seam line at regular intervals. [FPTS; p. 162]

\section{basting, press}

The process of creasing a seam edge by ironing or finger pressing. [FPTS; p. 162] 


\section{basting, slip}

A series of hand stitches alternating between the folded seam edge of one ply and the folded seam edge or seam line of another ply. [FPTS; p. 162]

\section{basting, tailor}

see "basting, diagonal"

\section{basting, uneven}

A series of hand stitches about 0.5 inch $(12.7 \mathrm{~mm})$ in length and at 0.125 inch $(3.2 \mathrm{~mm})$ intervals. Maybe used as a marking stitch. [FPTS; p. 163]

\section{beveling}

$$
\text { see "blending" }
$$

\section{bias (also spelled "byesse")}

1. A line diagonally across grain of fabric. [FDF; p. 40]

2. A strip of matching or contrasting fabric. In construction it is used to conceal, finish, and strengthen seams and raw edges, or as a substitute for facings. Maybe used as a decorative binding, piping, or tubing. [FPTS; p. 164]

3. A direction in the fabric at an angle to the lengthgrain or crossgrain. Is the direction in which the woven fabric has give. [FPTS; p. 68]

4. Of a fabric, occurs between the lengthwise and crosswise yarns. [GTAM; p. 104]

\section{bias binding}

Narrow strips of fabric "cut on the bias," thus pliable for use in covering raw edges of curved necklines and armholes, or used as trimming. [FDF; p. 40]

\section{bias cut}

1. Manner of cutting diagonally across grain of fabric, resulting in a garment that clings and follows body curves closely. [FDF; p. 40]

2. Manipulation of the bias or true bias of fabrics, to conform to the body curve and affecting the controlled fullness of the garment. Also referred to as "cut on the bias." [FPTS; p. 2]

\section{bias cutting}

Cutting a piece of fabric on a 45-degree angle to the selvage. [CLEM; p. 3]

\section{bias, forty-five degree see "bias, true"}

\section{bias, true}

1. The diagonal line that intersects the lengthgrain and crossgrain at a forty-five degree angle. Also called "forty-five degree bias." [FPTS; p. 68]

2. A line exactly 45 degrees from either warp or filling, and can be expected to stretch in response to gravity's pull. [GTAM; p. 104]

\section{binding}

1. Functional trim that encompasses outer edges of garment components. [AMFG; p. 514]

2. Sewing term for narrow fabric strips used to cover seams or raw edges of clothing, e.g., "bias binding" and "seam binding." [FDF; p. 41]

\section{bite}

The margin distance between the edge of fabric and the point of needle entry for a stitch. [CLEM; p. 4]

\section{blend}

1. The forming of a continuous seam line. [FPTS; p. 45]

2. The rounding, shaping, and smoothing of angular lines. [FPTS; p. 45]

3. The matching of corresponding style and seam lines. [FPTS; p. 45] 


\section{Apparel Manufacturing Glossary for Application Protocol Development}

\section{blending}

1. Fur-industry term for lightly applying dye to tips of hairs of furs, such as mink and sable, to improve the coloring. [FDF; p. 43]

2. Trimming to different widths all plies of the seam allowance in a completed seam. Also referred to as "beveling, layering, or grading." [FPTS; p. 306]

3. Combining compressed clumps of fibers from several different bales in the spinning process. [GTAM; p. 24]

\section{block}

A basic pattern. [AMFG; p. 514] also see "sloper"

\section{block, basic}

1. A set of pattern pieces that form the simplest garment of a particular type. [AMFG; p. 513]

2. A pattern with no design interest and with structural details in classic or traditional locations. It generally has no seam margins, which makes it easier to manipulate for styling. Is also called a "sloper," which see. [GTAM; p. 94]

\section{block chopping}

The cutting process which requires the shape of the component initially cut from the spread, to be cut again (trimmed with precision) after it leaves the spreading table. [AMHB; p. 120]

\section{block pattern}

see "sloper"

\section{block, styled}

Variations of individual pieces of a basic block, including both comfort and design ease.

[AMFG; p. 524]

\section{block system}

The trade name for drafting style patterns (men's, women's, or children's) without developing such patterns with the use of slopers. [AMHB; p. 84]

\section{blocking}

1. A pressing process in which the fabric or product encompasses a fixed form, the block, before pressure, heat or moisture is applied to the fabric in order to stabilize the fabric's conformance to the form of the fixed form. [AMHB; p. 311]

2. Process of shaping knitted clothing after completion or washing by drawing outline on paper and shaping article to conform. [FDF; p. 44]

3. Millinery term for placing a felt or straw hood over a block of wood, then using heat or steam for desired shape. [FDF; p. 44]

4. A process of realignment of lengthgrain and crossgrain yarns to a ninety degree angle by pulling on the true bias from the shorter off-grain edge, or by pulling and realigning the fabric on grain while pressing with steam. [FPTS; p. 68]

5. Gently coaxing the garment back to its original dimension on a towel or other absorbent surface while still wet. [GTAM; p. 36]

\section{bobbin}

1. A small metal or cardboard spool, which is approximately $1 / 2 "[\sim 13 \mathrm{~mm}]$ in diameter and $1 / 2 "$ [ 13 mm] long, where the mass supply of thread is carried. [AMHB; p. 202]

2. Device for holding lower thread supply on lockstitch machines. [AMFG; p. 514]

3. Small spool such as the one on which lower thread in sewing machine is wound. [FDF; p. 49]

4. In textile production, the spool or core on which yarn is wound, which has a hole to fit on the spindle. [FDF; p. 49]

5. Small spindle on which thread is wound when making lace, tatting, or knitting. [FDF; p. 49]

\section{bodice}

1. Since 19th century, term for close-fitting upper part of women's dress, sometimes cross-laced in peasant dresses. [FDF; p. 49]

2. The upper part of a woman's dress. [WEB 1; p. 123] 


\section{body}

1. The compact, solid, or firm feel of a fabric. [CLEM; p. 4]

2. Perfected pattern for a style that has been fitted and graded. [AMFG; p. 514]

3. A combination of styled blocks that create a particular style. [AMFG; p. 514]

4. Quality of a fabric that drapes well, hangs well, and stands up under use. [FDF; p. 50]

5. Term used from 15 th to 17 th century to denote woman's "bodice." [FDF; p. 50]

\section{body bulge}

Area of human body that protrudes out, e.g. the abdomen and bust, or chest. Compare with "point of articulation." [GTAM; p. 97]

\section{body type (human)}

A set of proportional relationships in body dimensions that is representative of some population segment. [AMFG; p. 514]

\section{bolt}

A roll or length of fabric; may vary in length. [CLEM; p. 4]

see also "cut"

\section{break point}

The section of a garment where a controlled change in direction occurs producing a roll, turn-back, or flare point. [FPTS; p. 38]

\section{bundle}

1. Cut-out pieces of dresses, shirts, etc., tied together with cord or elastic. [FDF; p. 72]

2. Garment-trade production term for cut-out pieces of dresses, shirts, etc., tied together with cord or elastic. [FDF; p. 72]

3. (n.) A stack of cut-out garment sections. [FPTS; p. 102]

4. (v.) Separated from the lay, folded, and/or tied. [FPTS; p. 102]

5. Garment parts which are grouped together for assembly. [AMFG; p. 514]

\section{bundle, garment}

Contains all the parts of a single garment. [AMHB; p. 461]

\section{bundle, job}

Contains the part or parts of the garment for the operations that are to be done on one or more work stations. All the parts of the garment do not move together in sequence from the first workstation to the last. [AMHB; p. 461]

\section{bundle system}

Garment-trade production term for method of production using an unorganized flow of sectionalized work with each employee bundling (their) finished work. [FDF; p. 72]

\section{bundle system, development}

Garment-industry term for production of sewn garments in which the items move in units or bundles in an organized manner from one operator to another. [FDF; p. 159]

\section{bundle system, "progressive"}

Is a term used incorrectly in many areas to define multiple flow systems which have no backtracking: systems built on the "product layout" principle, such as the "sub" assembly system, which is also based on product-layout principles. [AMHB; p. 460]

\section{bundling}

The process of sorting and stacking (with or without ties) cut components for further processing. [AMHB; p. 120]

\section{byesse}

\section{see "bias"}




\section{Apparel Manufacturing Glossary for Application Protocol Development}

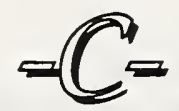

CAD

Computer-Aided Design

(may also denote Computer-Aided Drafting)

\section{capacity-requirement planning (CRP)}

A detailed and precise plan used to match the master production schedule to available plant production volume. [AMFG; p. 514]

\section{casing}

1. Fold of fabric stitched down to form a tunnel through which elastic, or a cord, is drawn. Sometimes made by a facing. [FDF; p. 96]

2. A fold-over edge or applied strip which is an integral part of a garment. Encloses a drawstring or an elastic to draw in the garment circumference to fit corresponding body areas. [FPTS; p. 171]

3. Elastic treatment at the waist.

[GTAM; p. 217]

4. A fabric or thread enclosure that conceals and/or prevents body contact with elastic or other materials. [AMFG; p. 514]

\section{chainstitch, multi-thread}

The needle thread passes through the material and is interlooped on the underside with the looper thread. [AMFG; p. 520]

\section{chainstitch, single-thread}

The needle thread passes through the material and is interlooped on the underside with the previous stitch. [AMFG; p. 523]

\section{chopping}

The process which actually cuts raw material into product components. Also referred to as "cutting" or "knifing." There are two major types of chopping: "block chopping" and "pattern chopping," which see. [AMHB; p. 120]

\section{CIM}

Computer-Integrated Manufacturing

\section{close-and-cup}

Used when trueing darts. One dartline is creased. The creased fold is matched to the opposite dartline and dart is pinned closed. Pattern is folded under at apex or dart point, and seamline crossing dart is trued. [KOPP; p. 3]

\section{CMT (stands for: cut, make \& trim)}

1. Contracts for manufacture of apparel are often written on a cut, make, and trim basis.

[GTAM; p. 52]

2. The cost to merchandising of the total to cut, make and supply trim for each dozen garments. [CLEM; p. 7]

\section{cockle}

1. Defect in fabrics that results in bumpiness or puckering in the finished goods. [FDF; p. 125]

2. 17th century term for woman's curl or ringlet. [FDF; p. 125]

\section{cockling}

A term describing any corrugated or rippled sewing line. It is either "gathering" or "puckering." [AMHB; p. 182]

\section{collection}

Term used by couture, ready-to-wear, or manufacturer's designer for clothing and accessories offered to customers for a specific season. Originally used only for high-priced couture clothing. Also called "line." [FDF; p. 134]

\section{computer pattern}

Sewing pattern developed in 1960's, made to fit the individual. Salesperson in store takes customer's measurements, which are then sent to a pattern company and fed to a computer to produce a customcut pattern for garment. [FDF; p. 136] 


\section{Computer-Aided Design (CAD)}

In the apparel industry, the application of computer technology to the development of a garment up to the point of production. Capabilities of CAD systems used in the apparel business have traditionally included pattern grading, marking making, and plotting. [AMFG; pgs. 136-137]

\section{computer-assisted design}

Methods developed in the mid-1980's by companies such as Gerber-Camsco, Lectra, Microdynamics, Toray, Asahi, and Investronica, to develop markers with the aid of computers. [GTAM; p. 146]

\section{Computer-Integrated Manufacturing (CIM)}

Links the strategic business plan with marketing, merchandising, materials management, production planning, and production management.

[AMFG; p. 514]

\section{construction detail}

Describes the construction features for the garment style (eg. style and position of front pocket) and the materials required for each of these features (eg. type of pocket trim). [GIT2; p. 3]

\section{converge}

Lines developed on the paper or muslin pattern which begin from a given point of a calculated measurement and end at their juncture to form a point or points, shaped seam line, or roll line. [FPTS; p. 45]

\section{copy}

A thin patternmaking paper is placed over the draft or sections of the draft, and pinned to prevent shifting. Using proper tools, lines, crossmarks, etc., are copied. [KOPP; p. 3]

\section{copy, line-for-line}

American interpretations of Parisian and Italian couture dresses made expressly for American stores. Compare with "knock-off." [FDF; p. 340]

\section{copyist}

Person in the apparel trade who makes replicas of designs - translating a high-priced item to a lower price for a manufacturer. [FDF; p. 138]

\section{cost}

1. The value given up in order to receive goods or services. [CLEM; p. 9]

2. The total dollar amount invested in a product. [CLEM; p. 9]

\section{cost estimating}

Final costing done prior to production and price setting. [AMFG; p. 515]

\section{costing}

Process of determining the costs of production and marketing each style in the product line.

[AMFG; p. 515]

\section{costing, direct}

A process of determining production costs considering only variable manufacturing costs. [AMFG; p. 516]

\section{costs, direct}

Costs that can be traced to the product(s) being produced. [AMFG; p. 516]

\section{costs, indirect}

Manufacturing costs not associated with specific units of production. [AMFG; p. 518]

\section{costs, variable}

Direct costs that increase or decrease in proportion to change in volume of production; on a per unit basis, the cost stays the same. [AMFG; p. 524] 


\section{count}

1. cotton ...; Numerical designation of yarn size. [AMFG; p. 515]

2. The number of warp and filling yearns in a square inch of woven fabric. [AMFG; p. 515]

3. ...of cloth; Textile-industry term for number of "warp" and "filling" yarns in a square inch of fabric. Expressed by first writing number of "warps," then number of "fillings," e.g., 72 x 64 would mean 72 warps and 64 fillings per square inch. Knit goods are counted in warpwise loops, called "courses." Also called "fabric count." [FDF; p. 143]

4. ... of yarn; Textile-industry term expressed in numbers given for the size of yarns in relationship to their length and weight. Also called "yarn number." [FDF; p. 143]

\section{counter book}

see "pattern book"

\section{course(s)}

1. A row of loops parallel to the fabric width in any knit cloth. [AMHB; p. 31]

see also "wale"

2. Textile-industry term for a "crosswise" or "fillingwise" row of loops in knitting. [FDF; p. 143]

\section{couture}

French word used throughout fashion industry to describe the original styles, the ultimate in fine sewing and tailoring, made of expensive fabrics, by designers. The designs are shown in collections twice a year - spring/summer and fall/winter. [FDF; p.143]

\section{coverstitch}

1. A stitch generally used to seam knits which consist of at least two needle threads, a looper thread, and a top spreader or cover thread; covers the seam. [CLEM; p. 10]

2. A stitch formation that has surface thread that covers a raw edge or seam. [AMFG; p. 515]

\section{crease}

The setting of a fold along grain or structural lines by pressure [FPTS; p. 39]

\section{creasing}

Is a molding process using mechanical pressure to form a crease pattern in fabric. This process is applied largely to folding over the edges of fabric prior to submitting the fabric to a sewing operation. [AMHB; p. 311]

\section{croquis}

A detailed sketch of a garment by a designer to guide pattern makers. It does not resemble a fashion sketch. It must be a faithful rendering of the original idea, including details of the structure, such as seams, darts, pleats, tucks, shirring, plackets, or other openings, and all trimmings, buttons, and the like. [GTAM; p. 88]

\section{cross seam}

see "seam, intersecting"

\section{crossgrain}

Yarn woven across the fabric from selvage to selvage. Referred to as weft thread, and is the filling yarn of woven fabric. It has more give under tension than lengthgrain. [FPTS; p. 69]

\section{crossmark(s)}

1. Short lines indicating intersecting and juxtaposition of seam or style lines from the model form to the muslin or fabric. [FPTS; p. 39]

2. A short line which crosses a seamline, dartline, tuck line, etc. Used to indicate seam joining, matching points, or stitching points. [KOPP; p. 3]

\section{CRP}

\section{Capacity-Requirement Planning}

\section{cupping}

The rolling or folding of a pattern section to allow the portion of the pattern being trued or pinned to lay flat [FPTS; p. 45] 


\section{custom-made}

Describing garments made by tailor or couture house for an individual customer following couturier's original design. Done by either fitting on a model form adjusted to the customer's measurements or by several personal fittings. [FDF; p. 153]

see also "made-to-measure"

\section{cut}

1. Trade term used in ready-to-wear industry for cutting out fabric preparatory to sewing.

[FDF; p. 153]

2. A length of "gray goods," approximately 60 yards [ 55 meters] long. Also called a "bolt."

[FDF; p. 153]

3. When doing, "cut" on the inside of the pencil line. This refers only to cutting finished outside lines on slopers and patterns to retain the original fit when copying and outlining. [KOPP; p. 3]

\section{cut-of-the-garment see "flare"}

\section{cut-on-the-bias \\ see "bias cut"}

\section{cutter}

Garment-production term for the person who cuts the fabric with an electric knife. [FDF; p. 153]

\section{cutting}

Includes spreading of the fabric, cutting, notching, or otherwise marking cut parts with guide marks for matching, assembling, and bundling, or other preparation required to ready the cut parts for sewing after the cutting has been done. [GTAM; p. 162]

also see "chopping" cutting line

see "line, cutting"

\section{cutting production}

Consists of all the processing activities involved in reducing bulk materials and bolts of fabrics and trimmings used in apparel and allied products, into the component parts making up the apparel product. The major categories of cutting production processing are marker making, spreading, "chopping" (knifing or cutting), positioning marking, shading, sloping, and bundling. [AMHB; p. 120]

\section{cutting-up trade}

Jargon used by textile industry for clothing manufacturers. [FDF; p. 153]

\section{cycle time}

1. Time required for manufacturing or re-order cycle. [AMFG; p. 515]

2. Length of time required to complete one operation. [AMFG; p. 515] 


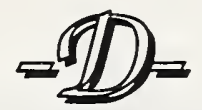

dart

1. (n.) A wedge-shaped fold of cloth which, when stitched, helps the cloth to conform to the shape of the body. [CLEM; p. 11]

2. Sewing term for V-shaped tuck used to make garment conform to the body. Used frequently at shoulders, waist, or in side seam under the arm. [FDF; p. 156]

3. (v.) The take-up of excess fabric, of a determined amount, at the edge of the garment and converging to a diminishing point. Darts formed to fit body contour vary in shape and size and may result in straight, concave, or convex converging pattern lines. The shape of a dart is indicated by convergent lines on the finished garment. [FPTS; p. 3]

4. A triangle which takes up fabric along a pattern edge and releases it into the interior portion of the garment near a bulge. [GTAM; p. 107]

5. (n.) A "V"-shaped, stitched fold starting at a certain width at one end and tapering to a point at the other end. [KOPP; p. 3]

\section{dart equivalent}

"Seams" that are shaped, and which contribute fullness at their apex, and remove or control fullness at the wide end. In an undarted blouse or shirt, which is tucked into a fitted waistband, the dart equivalent takes the form of folds of fabric. [GTAM; p. 107]

\section{dart, French}

Diagonal dart tapering to the apex; originating from any point between the hipline to two inches above the waist along the side seam. [FPTS; p. 3]

\section{dart manipulation}

The process of establishing the placement of one or more darts in any one of a variety of dart positions, from a basic one or two-dart concept, to a creative design. [FPTS; p. 46]

\section{dart manipulation, bust}

The single bust dart can be manipulated into any radius emanating from the bust point. Manipulating dart fullness into various areas is a major means of achieving different style features. Besides the waist position, the other five basic positions into which a bust dart is pivoted are: center front, neck, shoulder, armhole, and side. [AMHB; p. 75]

\section{dart slash}

A fitted dart constructed as a seam, designed so that one convergent line introducing gathers, dart tucks, or pleats, is of greater measure than the other. [FPTS; p. 4]

\section{dart substitution}

The process of manipulating and distributing dart pick-up from one or two dart concept into flange dart, dart tucks, tucks, released tucks, gathers, seams, or flares. Also referred to as "dart variation." [FPTS; p. 46]

\section{dart tuck}

The take-up of excess fabric, of a determined amount, at the edge of the garment and converging towards a point or points of release; is formed by the partial stitching of a dart along its convergent lines, releasing fullness. [FPTS; p. 5]

\section{dart underlay}

The area between the stitched lines of a dart. Also called "pickup." [KOPP; p. 3]

\section{DCL}

\section{Defect Classification List}

\section{dead head}

A spreading step in which material is being moved without being spread. [CLEM; p. 11]

\section{defect classification list (DCL)}

A detailed listing and description of each of the characteristics considered undesirable or below accept able standards of workmanship. [GTAM; p. 243] 


\section{depth surface interest}

In the context of "eye appeal," refers to the solid geometric contour of the garment surface as manifested by nap, pile, or trimming, such as buttons, clasps, braid, or lace. [AMHB; p. 54]

\section{design}

1. A specific or unique version of a style. [AMFG; p. 515]

2. The innovation aspect of product development. [AMFG; p. 515]

\section{design feature}

see "apparel design feature"

\section{design, structural}

1. Term used by dress designers for lines of dress which are concerned with the functional design of the dress, e.g., a zipper down the back of the dress, or pleats, as contrasted with "decorative design." [FDF; p. 553]

2. Textile term for a fabric, motif, or pattern achieved by weaving rather than surface treatment, e.g., fabric woven on a "Jacquard" loom.

[FDF; p. 553]

\section{design system}

see "apparel design system"

\section{designer}

1. (A person who) creates specific products in accord with the trend. The designer may create by making a sketch which is forwarded to the draper or patternmaker for execution. [AMHB; p. 55]

2. Person engaged in creating original clothing and accessories in various areas of the fashion industry. Some designers own their businesses; others are employed by manufacturers to develop collections of merchandise in ready-to-wear, couture, lingerie, millinery, footwear, accessories, and jewelry.

[FDF; p. 158] dot

1. A small round mark used to denote a specific point on a sloper or pattern, often indicated with an awl. [KOPP; p. 3]

2. pl., "dots" - round spots used as a pattern in regular rows or a random arrangement; e.g., "coin dots," larger than a dime; "pin dots," as small as the head of a pin. [FDF; p. 451]

\section{draft}

The intervening step in the development of a pattern by measurements or through the slash-andspread or pivot method, which includes all pertinent marks, lines, and information for the completion of the final pattern. Is used as a base to establish style lines, roll lines, break points, and design features. A "draft" does not include seam allowances. [FPTS; p. 32]

\section{drafting}

The technique of manipulating the sloper to achieve an original design. A set of slopers is "drafted" from measurements taken from a model form, a live model, or according to standardized or individual manufacturer's specifications. Also known as "flat pattern design." [FPTS; p. 30]

\section{drape}

1. The hang or fall of fabric when made into a garment is an important quality to consider in designing, e.g., chiffon has a soft drape, whereas ottoman hangs stiffly. [FDF; p. 169]

2. The tendency of fabric to change constructional dimension or "drape sense" when the orientation of the grain structure is changed with respect to gravitational forces. This applies to both static and dynamic situations [AMHB; p. 63] 


\section{drape plane}

Refers to the angle of inclination to the vertical. If the fabric is parallel to the horizontal, the drape plane is 0 degrees. A vertical suspension is 90 degrees. [AMHB; p. 38]

\section{drape sense}

In context of eye appeal in a garment, is the sense of rigidity or relaxation inherent in the product perimeter regardless of the static or dynamic situation. [AMHB; p. 54]

\section{draper}

see "patternmaker"

\section{draping}

1. Means of design in which fabric or representative is draped on three-dimensional form to derive patterns. [CLEM; p. 13]

2. Falling fabric in folds in the garment as seen on statues of ancient Greece. [FDF; p. 169]

3. Trade term for arranging and pinning muslin cloth over a dummy to conform to the design of the intended garment. After draping, muslin is removed from dummy, stitched at seams and tried on a model. Then it is altered, refitted on model, and cut at seams to make the pattern. [FDF; p. 169]

4. The process of cutting, pinning, slashing, and marking muslin or fabric in developing a pattern or design on the model form or live model. [FPTS; p. 40]

\section{dress form}

see "dummy" and "model form"

\section{dressmaker}

Person who makes clothing for private customers from pattern to finished garment, either by hand or by machine. From 1850 through 1920s, before ready-to-wear, dressmakers often worked in customers' homes to prepare seasonal wardrobes for the family. Also called a "seamstress." [FDF; p. 181]

\section{dressmaker's dummy}

see "dummy" and "model form"

\section{drill}

Durable cotton fabric made in a warp-faced twill similar to denim. Extra strong types are made with coarse carded yarns, sometimes made in a herringbone twill. [FDF; p. 182]

\section{drill hole}

A very small hole drilled through a cutting room bundle of a garment part to aid sewing operators in properly locating a smaller superimposed part, such as a pocket. [CLEM; p. 13]

\section{drop}

A term used generally to refer to secondary sections of a marker. Every marker must have at least one drop to utilize remnants. [CLEM; p. 13]

\section{dummy}

Dressmaking form in shape of human body on which the designer or home sewer drapes clothes before sewing. Also called "dress form," "dressmaker's dummy," "dressmaker's form," and "model form." [FDF; p. 183] 


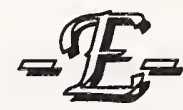

\section{ease}

1. Factor taken into consideration when drafting a pattern - allowing extra measure at bust, waist, and hips so garment will fit comfortably, not skintight. [FDF; p. 188]

2. Even distribution of fullness at a seam or style line controlling a minimal amount of fabric excess without forming gathers, tucks, or darts [FPTS; p. 5]

3. One of the standards of fit which suggests comfort of the garment, and ensures ease of activity and mobility for the wearer. It can be thought of as the measurable difference between the body size of the intended wearer and the garment. [GTAM; p. 119]

4. The difference between garment measurement and body measurement. There are primarily two types, wearing ease and design ease. [AMFG; p. 127]

5. design (or styling) ... ; Includes, in addition to wearing ease, whatever is built into the style to provide the look the designer wants. [AMFG; p. 127]

6. wearing (or comfort) ... ; Depends on manufacturers' standards for fit. Sleeve width is an example. [AMFG; p. 127]

\section{eased seam}

see "seam, eased"

\section{easing}

A process producing an even distribution of fullness by drawing in the bobbin thread of machine stitches applied to a seam line or edge. [FPTS; p. 303]

\section{edge finish}

Stitching that provides a finish for a single ply of fabric; may retain a folded edge or encompass a cut edge. [AMFG; p. 516]

\section{edging}

1. Trim used to accentuate style lines, outline shapes, or to compartmentalize blocks of color; piping, lace, ribbon, fringe, tape, picot trim, etc. [AMFG; p. 516]

2. Narrow decorative border of lace, embroidery, braid, or fringe used for trimming on clothing, particularly at hem, sleeve, or neck. [FDF; p. 188]

\section{EDI (electronic data interchange)}

Computerized, two-way exchange of information to facilitate ordering, manufacturing, or distribution of goods. [AMFG; p. 516]

\section{ergonomics}

Defined by Webster's as an applied science concerned with the characteristics of the body that need to be considered in the designing and arranging of workstations in order that the body and workstation will interact safely and effectively. [CLEM; p. 14] 


\section{Apparel Manufacturing Glossary for Application Protocol Development}

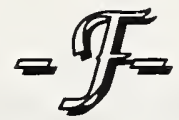

\section{fabric}

Cloth made of textile yarns by weaving, knitting, lace making, braiding, netting, or felting. Also, cloth made by bonding or non-woven methods. Derived from Latin, "fabrica," meaning "workshop." [FDF; p. 202]

\section{fabric count}

see "count, ... of cloth"

\section{fabric grading}

see "grading, fabric"

\section{fabric grain}

see "grain, fabric"

\section{fabric hand}

see "hand, fabric"

\section{fabric, shell}

The outer fabric of a garment.

[AMFG; p. 522]

\section{fabric utilization}

The percent of fabric actually used in garment pieces; remainder is waste. [AMFG; p. 516]

\section{fabrication}

The method used to produce the material; woven, knitted, molded, cast, etc. [AMFG; p. 516]

\section{face (of fabric)}

1. In apparel construction, is the side of the material viewed by the public. The other side is the "wrong" side. Both terms are relative terms determined by the dictates of the designer who uses the fabric. "Right side" is a synonymous term. [AMHB; p. 32]
2. Right side of fabric with better appearance - as opposed to back, or reverse side. Some fabrics are reversible and may be used on both sides.

[FDF; p. 202]

3. The surface of the fabric designated in the process of weaving, printing, finishing, to be used as the outside or face of a finished garment. Also referred to as "right side of fabric." [FPTS; p. 69]

4. ... side; The side of a fabric which is intended to be shown, and by reason of weave, or finish, presents a better appearance. Some fabrics do not have a "face side." [CLEM; p. 15]

\section{facing(s)}

Sewing term for self-fabric lining used on curved or irregularly shaped area of garment, e.g., neckline, lapels, collars, cuffs, or hem. Also called "parament." [FDF; p. 202]

\section{fashion}

1. The contemporary mode in wearing apparel or accessories as interpreted in textiles, fur, leather, and other materials. In the broader sense, it also involves the designing, manufacturing, promotion, and selling of such items. "High ..." denotes the mode of the moment - the current styles in apparel and accessories. These styles usually change from one season to the next. [FDF; p. 205]

2. All the clothes and accessories worn during a given historical period, e.g., "Elizabethan fashions." [FDF; p. 205]

3. "A continuing process of change in the styles of dress that are accepted and followed by a large segment of the public at any particular time."

[AMFG; p. 516, from Jarnow, Guerreiro, \& Judelle, 1981, p. 419]

\section{Fashion Group Inc., The}

An international professional association of women executives in fashion manufacturing, marketing, retailing, communication, and education. Founded in 1931 and based in New York, the Group circulates information among its members by means of fashion shows, exhibits, speeches, career courses, and discussion panels. [FDF; p. 205] 


\section{felling}

1. A trade term which refers to any operation in which a folded edge is sewed to the body of its own fabric or to any section of another fabric. [AMHB; p. 180]

2. A type of seam accomplished by lapping the fabric edges to hide raw edges; single or double needle stitching may be used. [CLEM; p. 16]

\section{figure form}

see "model form"

\section{filling}

Crosswise yarn of a fabric which runs at right angles to the selvage. Also called "pick," "woof," or "weft." Opposite of "warp" — the vertical yarns. [FDF; p. 211]

\section{fillingwise}

Textile industry term meaning across the fabric, or a right angles to the selvage. Also called "weft-" or "woofwise." [FDF; p. 211]

\section{fill repeat}

The distance between two points where the design is formed and again repeated along the length of the fabric. [CLEM; p. 16]

\section{findings}

1. Sewing or trade term for all the smaller items and trimmings that complete a garment, e.g., buttons, hooks, bindings, laces, etc. [FDF; p. 211]

2. Essential hardware and fasteners, pocketing, waistbanding, shoulder pads, interfacing, thread, labels, and other elements which help complete the structure of the garment. [GTAM; p. 51]

3. Materials used in garments others than piece goods; trims, threads, closures, labels, etc.

[AMFG; p.517] see also "notions"

\section{first pattern}

see "pattern, first" fit

1. How a garment conforms to or differs from a (human) body. [AMFG; p. 517]

2. A collection of vital measurements associated with various sizes of garments to be produced. [GIT2; p. 2]

3. standards of ...; Are composed of five nouns - ease, line, grain, balance, and set. The fit of any garment can be assessed by each of these standards. Fit is present when all five standards are satisfied, and lacking if any one of the five standards is absent. [GTAM; p. 119]

\section{fitted}

Describing a garment that conforms closely to body lines. [FDF; p. 212]

\section{fitting}

Trade term for dressmaker's or tailor's session with customer for altering garment to fit the figure. [FDF; p. 212]

\section{flare}

The result achieved by manipulating fabric, without darts, pleats, or gathers, to conform to a body contour, seam, or style lines affecting the controlled fullness at the lower edge of the garment. Also referred to as "cut of the garment." [FPTS; p. 3]

\section{foot space}

Term stipulating a unit of measure using the presser foot of a sewing machine as a guide. Foot space measurements may differ by sewing machine type and style of foot. [FPTS; p. 305]

\section{foundation}

Undergarment combining a bra and girdle in one piece to mold the figure. Formerly called a "foundation garment" or "garment" from about 1920 to the early 1980s. [FDF; p. 217]

\section{foundation pattern}

see "pattern, foundation" or "sloper" 
FSW

full seam width

\section{fused seam}

see "seam, fused"

\section{fusing}

The process of bonding fabric layers with an adhesive by the application of heat and pressure for a specific amount of time. [AMFG; p. 517]

\section{fusion}

1. Is a phenomena that takes place only in some synthetic yarns. Is caused by the needle heat generated as the needle oscillates in and out of the fabric. The heat of the needle is great enough to melt the yarns at the point of contact with the needle shaft; the yarns melt, part, and fuse. [AMHB; p. 219]

2. The degree with which fabric yarns are fused together by heat in the sewing action. [AMHB; p. 181]

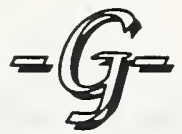

\section{garment}

Shortened form of the term "foundation garment." [FDF; p. 236] see also "apparel"

\section{garment components}

Garment parts that require one or more separate pieces to be assembled as a unit; the basic sections of garments; includes top fronts, top backs, bottom fronts, bottom backs, sleeves, collars/neckline treatments, cuffed/sleeves treatments, plackets, pockets, waistline treatments, and hems. [AMFG; p. 517]

\section{garment section, women's}

Portion of a garment delineated by seam or style lines forming a pattern piece; identified as front and back bodice, front and back skirt, yoke, midriff, princess panel, band and insert, sleeve, collar, and pocket. [FPTS; p. 47]

\section{garment specs}

see "specs; 1. garment ..."

\section{garment trade}

see "apparel industry"

\section{gather}

(n.) Formed by stitches concealed within the seam line and are not visible on the face of the garment. [FPTS; p. 10]

\section{gathering}

1. (n.) A corrugated sewing line whose finished sewed length is less than the original cut length of the fabric. [AMHB; p. 181]

2. Drawing up fullness by tightening of several threads in a row of stitching. Also see "shirring." [FDF; p. 237] 


\section{Apparel Manufacturing Glossary for Application Protocol Development}

\section{gauge}

1. Knitting term for number of stitches per unit of width and length in a knitted fabric. [FDF; p. 237]

2. Distance between needles. [AMFG; p. 517]

3. Related to number of wales per inch on knitted fabric. [AMFG; p. 517]

4. Distance between stitching lines made by multi-needle sewing machines. [AMFG; p. 517]

5. Various tools, rules, or guides, used to measure or mark apparel pieces in garment construction process. [FPTS; pgs. 145-146]

\section{gauging}

Two or more parallel rows of evenly-spaced running stitches drawn up to a controlled, predetermined fullness which correspond to a smaller adjoining seam, specified body measurement, or garment area. [FPTS; p. 6]

see also "shirring"

\section{girth}

A measure around a (human) body. [WEB1; p. 486]

\section{godet (go-day)}

Triangular piece, sometimes rounded at top and flaring at the base, set into a skirt or sleeve to give added fullness. [FDF; p. 254]

see also "gore" and "gusset"

\section{gore}

1. Skirt section, wider at hem than top, providing fullness and shaping to waist without using darts. A four-gore skirt has seams at sides, center front, and center back. There may be as many as twenty-four gores in a skirt. [FDF; p. 255] see also "gores, French"

2. Sewing term for a triangular insert of fabric that creates fullness, greater width, or desired shape. Used in skirts, bell-bottom pants, and gloves. Also called "godet." [FDF; p. 255]

\section{gores, French}

Term used in 1807 for panel introduced into skirts to eliminate gathers at the waist. [FDF; p. 220]

\section{grade}

1. The increase or decrease made to the base size to obtain another size is computed from either a list of body measurements for each size, or from a list of finished garment measurements for each size. [GTAM; p. 124]

2. An indicator of quality. [AMFG; p. 517]

3. An increase or decrease in a single size of a pattern. [AMFG; p. 517]

\section{grade points}

Points that are marked on a pattern and displaced according to the grade rules to obtain patterns for different sizes of garment. These points are referred to in the grade rules and marked on the pattern parts. [GIT2; p. 112]

\section{grade points, pattern}

Grade points marked on a particular pattern part. By displacing these points according to the grade rules, a pattern part can be reduced or enlarged for different garment sizes. [GIT2; p. 111]

\section{grade rule(s)}

1. The increments of vertical and/or horizontal movement of specific points on a sample size pattern that are required to make patterns for other sizes. [CLEM; p. 20]

2. The rule for grading a pattern to obtain a pattern for a particular size. [GIT2; p. 12]

3. The mathematical relationships between sizes. [GTAM; p. 146]

\section{grade table}

A collection of rules for grading a pattern of one size of garment to obtain the patterns for different-sized garments. [GIT2; p. 11] 


\section{graded pattern, nested}

Consists of a group of sizes of a pattern, in which the perimeter of the various sizes are drafted concentrically about each other, with the perimeter of the smallest size in the center, and the larger sizes drafted concentrically around it, progressively in size place, with the outermost perimeter, that of the largest size in the group. [AMHB; p. 112]

\section{grading}

1. Trimming to different widths all plies of the seam allowance in a completed seam. Also referred to as "blending, beveling, or layering." [FPTS; p. 306]

2. The process by which a series of consecutively sized apparel patterns is produced from a single existing pattern of the sample size. [GTAM; p. 123] see also "grading, pattern"

\section{grading, fabric}

Determining quality of the fabric by identifying the size or length of defects and the number of defects in the lot. [AMFG; p. 516]

\section{grading, pattern}

1. The drafting process of enlarging or diminishing a style pattern into patterns for other sizes. The function of (pattern) grading is to see that this is accomplished with proper fit for the other size(s) without changing the style sense of the original model. There are two basic methods for grading patterns - the track-shift method and the radial draft method. Both are governed by the same geometric principle, i.e. each must increase or decrease the pattern in the same manner in which the body perimeter changes in the size range. [AMHB; p. 93]

2 . The process of increasing or decreasing the dimensions of a pattern at specific points according to certain grade rules of proportional change. [AMFG; p. 520]

\section{grading, radial draft}

A method of drawing radial lines from the center of the pattern to all angles on the pattern perimeter. Each radial line is the hypotenuse of a right triangle whose altitude is equal to the height of this angle point from the pattern center. [AMHB; p. 108]

\section{grading table}

Is a scale of correlated length and girth measurements for a range of sizes. [AMHB; p. 94]

\section{grading, track-shift}

A method where vertical lines are drawn through the approximate center of all variable girth sections, and horizontal lines (perpendicular to vertical lines) are drawn through the approximate center of all variable length sections. [AMHB; p. 108]

\section{grain}

1. The direction of a weave in a fabric. [CLEM; p. 20]

2. Textile and sewing term which means "warpwise" or lengthwise of the fabric. To cut "against the grain" means "fillingwise" or across the fabric.

[FDF; p. 256]

3. Leather term for the markings which appear on the skins and hides when the hair or feathers are removed. [FDF; p. 256]

4. Measure used to determine the weight of pearls and sometimes diamonds, equal to 50 milligrams or $1 / 4$ carat. [FDF; p. 256]

5. One of the standards of fit, and is the direction fabric takes on the body, and is determined from the direction and placement of the pattern pieces in the marker. [GTAM; p. 120]

\section{grain, bias}

Is parallel to the bi-sector of the right angle formed by the intersecting straight and cross grains. [AMHB; p. 32]

\section{grain, cross}

Is the grain parallel to the filling in woven fabrics, and the course (grain) in knitted fabric. [AMHB; p. 32] 


\section{grain, fabric}

All yarn-constructed fabric have three basic grain lines - straight, cross, and bias. [AMHB; p. 32]

\section{grain line(s)}

The three basic lines, straight, cross, and bias, which all yarn-constructed fabrics have. [AMHB; p. 32]

\section{grain, off}

A fabric whose lengthgrain and crossgrain threads have been distorted from a ninety-degree alignment, or when crossgrain is not at right angles to selvages or length of goods. "Off-grain" fabric can be re-aligned or put "on grain" through straightening and blocking. [FPTS; p. 69]

\section{grain, off-bias}

As a follow on to "grain, bias," are all other grain lines passing through the right angle. [AMHB; p. 32]

grain, on

A fabric whose lengthgrain and crossgrain threads or yarns intersect each other at right angles. [FPTS; p. 70]

\section{grain, straight}

In woven fabrics, it is the grain parallel to the warp yarns; in knitted fabrics, it is parallel to the wales. "Warp grain" and "length grain" are other trade terms used for this grain. [AMHB; p. 32]

\section{grain, support}

The grain which supports the fabric during movement. Pile and napped fabrics have two support grains for each of the three basic grains, one for each direction of grain. [AMHB; p. 38]

\section{grainline}

1. Marking on a pattern piece used for alignment with warp yarns or walelines in piece goods and positioning patterns in markers. [AMFG; p. 517]

2 . Lines drawn on the lengthgrains and crossgrains of muslin which identify grain and guide lines on the finished pattern. [FPTS; p. 42]

3. A mark carefully aligned parallel to selvages atop a single warp yarn. [GTAM; p. 40]

\section{grainline indicator}

A straight line with an arrow on each end drawn on the draft and final pattern pieces indicating the direction of lengthgrain [FPTS; p. 33]

\section{gray goods}

Textile term to describe unfinished fabrics as they come from the loom. Some fabrics may be millfinished, but most are sent to "converters" for the finishing processes. Originally called "greige goods," derived from the French, "grege," meaning "raw." [FDF; p. 257]

\section{greige goods}

1. Fabrics of all fibers in an unfinished state. [CLEM; p. 20]

2. After they have been woven and before dyeing or finishing. [CLEM; p. 20] see also "gray goods"

\section{guide line(s)}

Lines drawn on the prepared muslin to aid draping, indicate body parts and features, to control grain placement, and as structural lines. [FPTS; p. 42]

\section{guide-line, cutting}

A drawn line on the traced sloper or draft. Used as a guide for slashing, and is calculated on the sloper to facilitate specific pattern change and/or development. [FPTS; p. 32] 


\section{gusset}

1. Sewing term for diamond-shaped piece of fabric inserted under the arm of sleeve to permit greater movement. [FDF; p. 259]

2. Triangular piece used at sides of handbag, at sides of men's shirttails, and sides of shoes for wider opening. [FDF; p. 259]

3. A diamond-shaped unit of one or more pieces designed to be inserted into a slashed opening on a larger garment section or sections. [FPTS; p. 295]

4. Triangular or diamond-shaped piece of cloth inserted in a garment to strengthen or enlarge some part. [CLEM; p. 20]

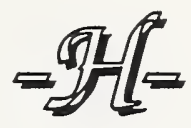

\section{hand}

1. Term used to describe a number of (fabric) factors, including degree of drape, stiffness or softness obtained after fusing to outer shell material. [also called "handle"] [CLEM; p. 20]

2. Qualities of fabric revealed through sense of touch, e.g., crisp or soft, smooth or rough. [FDF; p. 267]

3. One of the characteristics of fabric critical to the successful look and feel of a fashion garment. Has to do with the bending property of a fabric. Is another way to describe its drape. The bending property or quotient can be expressed numerically.

[GTAM; p. 44]

see also "KES"

4. The tactile sensation caused by the fabric and its consequent drape. It is one of the important aesthetic characteristics of apparel fabric. [GTAM; p. 62]

\section{hand, fabric}

1. The body or firmness of a fabric. [CLEM; p. 15]

2. Hand characteristics are the changes of the fabric plane with hand manipulations which exert tensile, compression, molding, or supporting forces on the fabric. They include some of the utility characteristics. The following characteristics are dimensions of fabric hand: (1) thickness compressibility; (2) plane compressibility; (3) elongation; (4) elasticity; (5) torsion; (6) malleability; (7) flexibility - self-flex, resistance flex, maintenance-flex, and reflex; (8) resilience; and (9) gravity drape, gravity sag, and gravity elongation. [AMHB; p. 36]

\section{haute couture (oht koo-toor)}

Top designers of custom-made clothes. Term originally applied to top designers in France. Derived from French, meaning "highest-quality dressmaking." [FDF; p. 282] 


$$
=\sqrt{2}
$$

\section{I.L.G.W.U.}

International Ladies' Garment Workers' Union

\section{inchering}

Eighteenth-century term for taking measurements of a person in order to make a garment. [FDF; p. 297]

\section{in lay}

Any operation or result that applies to the spread of fabric on the cutting table before it is cut apart and moved. [CLEM; p. 21]

\section{interfacing}

Canvas of linen, linen and hair, unbleached muslin, and crinoline fabric inserted between the outside and the facing of a tailored garment to give body and shape. [FDF; p. 299]

\section{interlining}

1. Materials that are fused or sewn to specific areas inside garments or garment components; provides shape, support, stabilization, reinforcement, hand, and improved performance. [AMFG; p. 518]

2. Fabrics used between the lining and the outer fabric of a coat, collar, or suit to give shape to the garment. [FDF; p. 299]

3. Open weave woolen or cotton fabric used between the lining and outer fabric in a winter coat to give warmth. Same as "interfacing." [FDF; p. 299]

\section{International Ladies' Garment Workers' Union (I.L.G.W.U.)}

A semi-industrial union founded in 1900 of U.S. and Canadian needle-trades workers, and originally an affiliate of the American Federation of Labor (AFL). [FDF; p. 299]

\section{JIT (Just-In-Time)}

A manufacturing management philosophy which dictates that raw materials and semi-processed materials arrive at their destination at the appropriate time with only the minimum quantity. [CLEM; p. 23]

\section{JQS (Job Quality Specifications)}

The written specifications and requirements for individual production operations which state precisely, succinctly, and clearly, the workmanship standards expected of the operator. They are best as written instructions (rather than verbal) supported by drawings, sketches, and even photographs.

[GTAM; p. 242] 


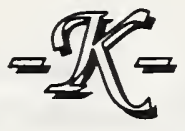

\section{KES (Kawabata Evaluation System)}

A scientific method, developed in Japan by Professor Kawabata, for evaluating (fabric) properties which have never before been measurable. The system is in response to the professed need to be able to predict sewability of fabric long before it arrives at the sewing station. [GTAM; p. 44]

\section{knifing}

see "chopping"

\section{knock-off}

1. A copy, adaptation, or modification of a style from another firm's line; usually offered for sale at a lower price than the original.

[AMFG; p. 133, 518]

2. Trade term for the copying of an item of apparel, e.g., a dress or coat, in a lower price line. Compare with "piracy." [FDF; p. 320]

3. A much less expensive version of an original (garment). [GTAM; p. 88]

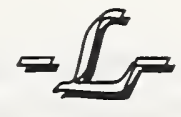

laid up

see "spread"

lay

1. The completed spread of all layers of cloth on the cutting table consisting of one cut or lot.

[CLEM; p. 23]

also see "spread"

2. in ...; see "in lay"

\section{layered}

Adjective used from late 1960s for clothing and sleeves of varying lengths worn one on top of the other. [FDF; p. 332]

\section{layering}

see "blending"

\section{laying in}

see "pattern pieces; 1. interlock"

\section{layout (of pattern pieces)}

see "pattern pieces; 2. layout of ..."

\section{layout, bi-fold}

see "layout, double lengthwise fold"

\section{layout, combination fold}

A spreading method where fabric is folded two different ways for same layout - one section of the fabric folded on the lengthgrain, or bi-folded, and the other folded crossgrain. [FPTS; p. 72]

\section{layout, crosswise fold}

A spreading method where fabric is folded on the crossgrain with each selvage aligned over itself. [FPTS; p. 72] 


\section{layout, double lengthwise fold}

A spreading method where fabric is folded on the lengthgrain with selvages aligned near or on the center of goods. Also known as "bi-fold layout." [FPTS; p. 73]

\section{layout, double-ply}

A spreading method where two or more plies of fabric are spread face-up or face-to-face. Also known as "multi-ply layout." [FPTS; p. 73]

\section{layout, lengthwise fold}

A spreading method where fabric is folded on the lengthgrain with opposite selvages aligned one over the other. [FPTS; p. 72]

\section{layout, multi-ply}

see "layout, double-ply"

\section{layout, open-ply spread}

see "layout, single-ply spread"

\section{layout, partial-lengthwise fold}

A spreading method where fabric is folded on the lengthgrain with one selvage aligned a measured distance from the fold - the balance of the fabric width is a single ply. [FPTS; p. 73]

\section{layout, single-ply spread}

A spreading method that utilizes a single ply of fabric. [FPTS; p. 74]

layup

$$
\text { see "spread" }
$$

\section{length}

Lower edge of item of apparel - the hem of a coat, jacket, skirt, or dress. [FDF; p. 336]

\section{lengthgrain}

Yarn paralleling the selvage in woven goods. Referred to as warp thread, warp yarn, or "straight-ofgoods." It is firmer, stronger, and more stable than crossgrain, and has little give under tension. [FPTS; p. 69] line

1. One of the standards of fit, and is a reference to the direction of seams, centers, and silhouette edges of a garment. They should trace the body's points of articulation and be, or at least appear to be, perpendicular or parallel to the floor.

[GTAM; p. 119]

2. A straight or curved geometric element that is generated by a moving point and that has extension only along the path of the point. [WEB $1 ;$ p. $668,8 a$ ]

3. Something, as a ridge or seam, that is distinct, elongated, and narrow, as a wrinkle, for example. [WEB1; p. 668, 3a]

$$
\begin{aligned}
& \text { 4. ... of clothes; } \\
& \text { see "collection" }
\end{aligned}
$$

\section{line balance}

In the context of "eye appeal,surface interest," refers to the plane geometric configuration that exists on the garment surface as manifested by effects such as yoke and panel seams. [AMHB; p. 54]

\section{line, break-point}

Strategic markings or drawn lines placed on a pattern. Used to indicate the point of change in the direction on a controlled turn, roll, or flare, planned on the finished garment. [FPTS; p. 31]

\section{line, cutting}

The edge of a muslin or paper pattern piece or pattern outline as drawn on the marker. [FPTS; p. 103]

\section{line, fold}

A design line indicating where a fabric ply is to be doubled back upon itself. [FPTS; p. 46] 
line, grain (or guide)

see "grain line(s)," "grainline, " and "guide line(s)"

\section{line, product}

A grouping of related merchandise designed for a specific target market. [AMFG; p. 521]

\section{line, roll}

A strategic line placed while developing a pattern. [FPTS; p. 35]

\section{line, seam}

1. Is the designated line along which the seam is to be joined. [FPTS; p. 238]

2. A line established on a pattern, indicating stitching lines of a garment section. [FPTS; p. 48]

3. ..., directional; that portion of a seam allowance or hem which when folded back is traced to correspond to the shape or angle of the pattern piece or section. [FPTS; p. 48]

\section{line, style}

A delineation representing a design line, seam line, or finished edge. [FPTS; p. 49]

\section{lining}

1. Materials that increase aesthetics and performance by supporting and/or enclosing the interiors of garments or garment components. [AMFG; p. 519]

2. Fabric, pile fabric, or fur used to finish inside of garment. [FDF; p. 341]

\section{list (or listing)} see "selvage"

\section{lock stitch (or lockstitch)}

see "stitch, lock" lot

1. A unit of production, a group of units, or packages. [AMFG; p. 519]

2. Used for identification, statistical sampling, or shipment. [AMFG; p. 519]

3. May be used in reference to materials, garment parts, or finished goods. [CLEM; p. 24]

4. A number of units of an article or a parcel of articles offered as one item. [WEB 1; p. 681] 


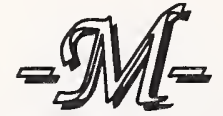

\section{made-to-measure}

Dress or suit made according to an individual's measurement. This type of clothing is primarily make in Hong Kong; no fittings are necessary. [FDF; p. 360]

see also "custom-made" and "tailor-made"

\section{made-to-order}

Produced after products were ordered by a buyer. [AMFG; p. 519]

\section{made-to-specifications}

Manufactured according to criteria provided by the buyer. [AMFG; p. 519]

\section{mark-off}

In fabric, is the phenomena of changing the shade and/or intensity of the fabric by rubbing it. [AMHB; p. 38]

\section{marker}

1. Diagram or arrangement of the pattern pieces for style(s) and size(s) that are to be cut at one time. [AMFG; p. 519]

2. A cutting guide comprising the outline of all production pattern pieces for one style in one or more sizes. [FPTS; p. 103]

\section{marker, blocked}

Pattern pieces laid out in groups by size to form rectangular sections that can be used separately or joined together to form a multiple-size marker. [AMFG; p. 514]

\section{marker, closed}

Made with half pattern pieces and used primarily for tubular goods. [AMFG; p. 514]

\section{marker efficiency}

Percent of fabric utilization. [AMFG; p. 519]

\section{marker making}

1. Is the process of developing the jigsaw-like diagram which is superposed on the top of a group of superposed plies as a guide for cutting these plies of fabric into the requires component parts of this manufactured product. [AMHB; p. 120]

2. Process of arranging pattern pieces in a most economical manner for cutting. [AMFG; p. 519]

\section{marker mode}

Orientation of pattern pieces within a marker: nap-either-way (N/E/W); nap-one-way (N/O/W); napup-and-down (N/U/D). [AMFG; p. 397, 519]

\section{marking}

Process of transferring marks from patterns to garment pieces to assist operators with assembly. [AMFG; p. 519]

\section{marking, positioning}

The process of placing guide marks on the surface and/or perimeter of cut components. These guide marks are followed by the assembly operators in order to make precise alignment in assemblies. [AMHB; p. 120]

\section{markings}

The construction symbols transferred from the pattern to the garment section after cutting. They indicate the position of points of construction, design detail, grainlines, and center lines. Also known as "tracings." [FPTS; p. 51]

\section{master}

see "sloper"

\section{master pattern}

see "sloper" and "basic block"

\section{measurement}

A collection of vital measurements associated with each size in a fit. For example, seat, bottom, knee, and outer seam measurements for size 32/32 in a particular fit. [GIT2; p. 10] 


\section{mitering}

Making a square corner when sewing by cutting the two edges in a diagonal manner and stitching them together. [FDF; p. 373]

\section{model}

1. American term for person who is paid to wear a garment in a fashion show or for a photograph. [FDF; p. 374]

2. French term for the garment itself. [FDF; p. 374]

\section{model form}

A standardized duplication of a human torso, cotton-padded and canvas-covered, set on a movable, height-adjustable stand. Also called "figure" or "dress form." [FPTS; p. 19]

see also "dummy"

\section{model size}

see "size, base"

\section{muslin}

1. Plain weave fabric made in many weights, from very fine and sheer, to coarse and heavy. [FDF; p. 381]

2. A plain weave fabric made from bleached or unbleached carded yarns which varies in weight, from fine to heavy, and in texture, from soft to coarse. [FPTS; p. 19]

\section{muslin pattern}

1. Complete garment made in an inexpensive fabric, e.g., muslin, usually draped on a dummy and, after muslin garment is finished, taken apart to provide a pattern for actual garment. [FDF; p. 381]

2. Process used for fur designing. Also called a "toile." [FDF; p. 381]

\section{muslin proof}

A muslin reproduction of the finished drafted pattern, pinned or stitched together in the form of the garment. Also referred to as "test muslin pattern." [FPTS; p. 56]

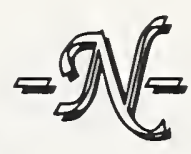

\section{nest, graded (or "nested set")}

A group of consecutively-sized graded patterns, all drawn on a single sheet of pattern paper, so that the boundary lines of each larger piece appear outside and parallel to the lines of the smaller size. [GTAM; p. 126]

\section{notch}

1. A mark or set of marks placed on the perimeter of a sloper, or across a seam line on the muslin or paper pattern. [FPTS; p. 47]

2. pl.(-es) Crossmarks transferred from seamline to edge of seam allowance, using a notcher. Are used on finished patterns. [KOPP; p. 3]

\section{notcher}

A punching tool which produces a 0.25 inch $(6.35 \mathrm{~mm})$ narrow $V$-shaped cut. Used to make notches on the edge of a sloper or paper pattern. [FPTS; p. 20]

\section{notching}

1. The process of clipping to remove a small wedge of fabric from seam allowance plies. [FPTS; p. 306]

2. The end result of cutting an incision through all fabric plies, or a " $\mathrm{V}$ " shaped notch on the perimeter of a pattern piece. [FPTS; p. 103]

\section{notions}

Together with "findings," which see, are considered supplementary items used in manufacturing all types of garments. Essential are those needed for construction procedures performed on any garment. [FPTS; p. 139] 


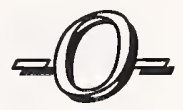

off grain

see "grain, off"

\section{off-the-peg}

British expression for buying ready-made clothes from retail stores rather than custom-made clothing. [FDF; p. 398]

\section{on grain}

see "grain, on"

\section{outline}

(v.) The process of drawing a line along the edge of the sloper or draft without seam allowances. [KOPP; p. 3]

\section{panel}

A determined measure of fabric planned for developing a design which features vertical style lines. [FPTS; p. 43]

\section{panel print}

A large design intended to be used in one length, without repeating, e.g., one panel used for front - one for back of dress. Usually made with hand-screened process and expensive. [FDF; p. 452]

\section{pants, proportioned \\ see "proportioned pants"}

\section{parament}

see "facing(s)"

\section{pattern}

1. A guide for cutting one or more garments. It includes all the pieces needed to make a garment. A patten for a garment style is graded by the readyto-wear manufacturer or commercial pattern company to include the size range within a figure type. Patterns conform to standard measurements, but interpretation of the measurements for sizing in the ready-towear market vary with each manufacturer and differ from commercial pattern standards. [FPTS; p. 54]

2. A collection of shapes for the parts of a garment style; is usually standardized for a particular size. Exact shapes for each size in the style are obtained by grading the pattern. [GIT2; p. 14]

3. perimeter of ...; see "line, cutting"

\section{pattern, base}

The basic template for generating a pattern for a garment style. A base pattern roughly conforming to the shape of the garment style is selected and modified to obtain the pattern for that style. [GIT2; p. 13]

see also "sloper" 


\section{pattern, basic}

see "sloper" and "basic block"

\section{pattern book}

Large volume issued regularly (and updated) by the publisher of paper patterns for home sewers showing all of the designs available. Also called "counter book." [FDF; p. 425]

\section{pattern chopping}

The process of cutting the fabric into the exact shape required for the final assembling operators (sewing or otherwise). [AMHB; p. 120]

\section{pattern, commercial}

An individually packaged pattern with symbols, markings and instructions printed on each garment section and accompanied by a detailed instruction sheet for pattern layout and garment construction. [FPTS; p. 55]

\section{pattern design, flat}

see "drafting"

\section{pattern, drafted}

A pattern that is developed through flat pattern design using measurements taken from the model form or live model from standardized or individual manufacturer's specifications, or through manipulation of drafted slopers. [FPTS; p. 55]

\section{pattern, draped}

A pattern that is developed through the manipulation of muslin or fabric on the model form or on a live model. [FPTS; p. 55]

\section{pattern, final}

The paper pattern of individual sections drawn from the draft which includes trued seam lines, seam allowances, notches, grainlines, and pattern identification. [FPTS; p. 33]

\section{pattern, first}

Original paper pattern created from the designer's sketch, draft, or drape, and specifications. [AMFG; p. 517]

\section{pattern, foundation}

One used as the basis for developing groups of designs. [AMHB; p. 55]

see also "sloper"

\section{pattern, graded}

Individual patterns of a particular garment or style proportioned to a set of standardized body measurements for each size within a size range. [FPTS; p. 56]

\section{pattern grading}

see "grading, pattern"

\section{pattern identification}

Words, numbers, and symbols placed on the individual sections of the final pattern. [FPTS; p. 34]

pattern, master

see "sloper" and "basic block"

\section{pattern, muslin}

see "muslin pattern"

\section{pattern part}

1. Is the shape associated with each part of the garment style. For example, the shape of the front leg panel of a trouser. [GIT2; p. 15]

2. graded ...; Is a pattern part graded for a particular size of garment. [GIT2; p. 16]

\section{pattern pieces}

1. interlocking of ...; The juxtaposition of pattern pieces or slopers of similar outline and the optimum arrangement of dissimilar pieces. Sometimes referred to as "laying in." [FPTS; p. 102]

2. layout of ...; The planned arrangement of interlocking pattern pieces on paper or fabric in preparation for cutting. [FPTS; p. 102] 


\section{pattern, production}

1. A granite-board copy of the tested and perfected final pattern including the specified seam allowances, perforations, notches, grainlines, and pattern identifications. [FPTS; p. 56]

2. Perfect, final patterns that meet all quality and production requirements, including seam allowances and markings. [AMFG; p. 521]

\section{pattern, sample size}

Is developed by adding to body measurements at various locations the amount anticipated as "ease." The pattern is traced on fabric, and garments are cut and sewn as samples. They are tried on selected persons and evaluated for fit and appearance. [GTAM; p. 122]

\section{pattern, standard block}

see "pattern, trade block"

\section{pattern, symmetrically matched}

One that is matched in two pieces of a garment at a seam, or any other place where they will be joined, so that not only do the horizontal lines match at the seam, but the vertical lines (or lines parallel to the seam) will be the same distance on either side. [CLEM; p. 41]

\section{pattern, trade block}

A granite-board pattern of a garment section, including seam allowances, notches, and details, which represents a basic or recurring fashion silhouette. Also called "standard block pattern." [FPTS; p. 57]

\section{patternmaker}

A person who drafts the pattern necessary to produce the creation. Also referred to as a "draper." [AMHB; p. 55]

\section{patternmaking lines, balancing} see "balancing; 3. ... patternmaking lines"

\section{pick}

Textile term for one yarn which runs at right angles to the selvage. Also called "filling," "welf," or "woof." [FDF; p. 431]

\section{pick-up}

An initial phase or task in sewing-machine operations, that starts when the operator's hands(s) begins to travel toward the fabric, and ends when the fabric is grasped by the hand. [AMHB; p. 274]

\section{pickup \\ see "dart underlay"}

\section{piece}

Mill term for fifty yards of fabric - or the amount that can be dyed in one vat. [FDF; p. 432]

\section{piece goods}

1. Fabric sold by the yard. Piece-good departments in retail stores sell fabrics by the yard to customers for home sewing. In the early days of retailing, few ready-made dresses were sold, so this department was one of the largest in the store. Also called "yard goods." [FDF; p. 432]

2. Fabrics that are cut and assembled into garments; includes shell fabrics, linings, and interlinings. [AMFG; p. 520]

\section{pin}

1. Useful device used as a temporary fastener, or when sewing. [FDF; p.434]

2. Ornamental jewelry made with a pin fastener on back, and usually having a safety catch. Also called a "brooch." [FDF; p. 434]

\section{pin basting \\ see "basting, pin"}

\section{pin tack(s)}

Formed by superimposing two or more stitch links on top of each other. [AMHB; p. 293] 


\section{pinching}

Is an individual miniature pleat in the sewing line. [AMHB; p. 182]

\section{pinking}

1. A common (sewing machine) finishing operation. [AMHB; p. 249]

2. Unhemmed border of fabric cut with sawtoothed edge to prevent raveling by using special "pinking scissors" or shears that have saw-toothed blades. [FDF; p. 435]

3. Decorative effect made by cutting short slits to form a pattern in shoes or garments, in late 15 th to 17th century. Also called "pouncing." [FDF; p. 435]

4. Saw-toothed trimming on edges of leather used in contrasting color on extra pieces applied to toes and heels of spectator and golf shoes for a decorative effect. [FDF; p. 435]

5. A method of cutting the raw edges of fabric to prevent raveling by imparting a saw tooth edge using a pinking machine or shears. [CLEM; p. 29]

\section{pipeline}

The name now bestowed on the process through which fiber evolves to garment at retail. [GTAM; p. 9]

\section{piping}

Covered cord that forms a raised edge along seams; used to stabilize seams, outline garment components, and absorb wear and abrasion that would otherwise degrade seams. [AMFG; p. 521]

\section{piracy}

Stealing of an idea for a dress by making sketches of it. Punishable as a crime in France where dress designs are protected by the French government. Not considered a crime in the U.S. unless the design is patented. Viewers at couture showings are permitted to mark their programs, but not permitted to make sketches. [FDF; p. 436]

see also "knock-off"

\section{pivot point}

A designated position on the sloper calculated to facilitate manipulation in the development of the desired design. Predetermined by the design element of a garment section. [FPTS; p. 34]

\section{pivoting}

1. A method of changing direction of a continuous line of machine stitching. [FPTS; p. 306]

2 . The shifting or moving of a sloper on pattern paper from a marked position towards a designated guide line. Used in the process of developing a new design, and as an alternative to or in conjunction with the "slash-and-spread" method to manipulate the sloper. [FPTS; p. 34]

\section{placket}

A structural opening in a garment. [AMFG; p. 520]

\section{pleat}

1. (n.) Fold of fabric usually pressed flat, but sometimes left unpressed. When used in a shirt, blouse, or dress, it is sometimes stitched down at the top of the garment to make it hand better. In polyester and nylon fabrics, pleats may by put in permanently with a heat-setting process. [FDF; p. 439]

2. (v.) To set in folds. Formerly spelled "plait." [FDF; p. 439]

3. (n.) Fold in fabric used as a means of adding fullness and motion to a garment. It creates a vertical line design and facilitates ease of body movement and action. [FPTS; p. 1]

4. (v.) The take up of excess fabric at the edge of a garment by means of doubling the fabric ply upon itself, producing a fold and forming an underlay of $5 / 8$ to 2 inches (15.875 to $50.8 \mathrm{~mm}$ ). [FPTS; p. 6]

\section{pleat, accordion}

1. Pressed in pleats; sometimes heat-set; small at top, but larger at bottom. Lower edge of hem shows a zigzag pattern. [FDF; p. 439]

2. Creased edges which can be superposed parallel onto each other at the creased edges without otherwise disturbing the fabric surface. [AMHB; p. 338] 


\section{pleat, angular}

Consists of a specific crease with a linear apex. Also known as a "knife pleat." Is either a side or accordion type. [AMHB; p. 338]

\section{pleat, dimensional}

A fold permanently set into a pattern of creased ridges or fluting. [FPTS; p. 1]

\section{pleat, flat}

May be folded and left unpressed, creased, or stitched to a designated length. They may be planned singly, in groups, or in evenly spaced series. [FPTS; p. 1]

\section{pleat, knife}

Pressed in pleats, usually placed one-half to $1 "$ [ 13 - $25 \mathrm{~mm}]$ apart, with all pleats going in the same direction. [FDF; p. 440]

\section{pleat, round}

A fixed, corrugated or billowed area in the fabric plane. It has definite amplitude and length in the curved wave pattern. [AMHB; p. 338]

\section{pleat, side}

Is a creased edge which lies adjacent to the fabric surface. [AMHB; p. 338]

\section{pleat tucking \\ see "tucking" (knife)}

\section{pleating}

1. Is any molding process which uses mechanical pressure to mold a series of creases or eruptions in the surface contour of a fabric. [AMHB; p. 311]

2. The process of setting a series of specific angular or curved folds with pressure, heat, and/or moisture in a flat piece of fabric. The angular or curved folds may be defined as "pleating" or "pleats." There are two major categories - angular and round. [AMHB; p. 338] ply

1. (sing.) A single layer of fabric.

[FPTS; p. 104]

2. (pl.) "plies" - two or more layers of fabric. Also referred to as "multi-plies." [FPTS; p. 104]

\section{ply count}

The number of singles, generally from two to six, which are twisted together to form the final thread. [GTAM; p. 72]

\section{ply yarn}

A number of individual yarns, or singles, twisted together to form a heavier yarn. [FDF; p. 441]

\section{point, break}

see "break point"

\section{point of articulation}

A body bulge which occurs because two body parts are hinged together, such as the elbow, shoulder, or knee. [GTAM; p. 97]

\section{prêt-à-porter (pret-ah-por-tay)}

French term for "ready-to-wear" clothes. Derived from "ready to be carried." [FDF; p. 449]

\section{printing}

Method of applying a pattern to a fabric in color. [FDF; p. 453]

\section{processing}

The terms "stitching" and "sewing" are also used to denote this. [AMHB; p. 170]

\section{proportion}

The harmonious interrelationship of silhouette, design feature, style line, and fabric grainline in a given design with regard to figure type. [FPTS; p. 1]

\section{proportioned hose}

Hosiery designed to fit different types of legs, e.g., extra long, full above-the-knee, long, short, and average. [FDF; p. 294] 


\section{proportioned pants}

1. (Women) Any pants for women made in petite, average, and tall sizes. Particularly, women's stretch pants since 1950s. [FDF; p. 419]

2. (Men) Trousers sold by inseam lengths of 27,29 , and 31 " $[69,74, \& 79 \mathrm{~cm}]$, as short, regular, and long. [FDF; p. 419]

\section{puckering}

1. A corrugated sewing line whose finished sewed length is equal to, or more than, its original cut length. Is often confused with "gathering."

[AMHB; p. 182]

2. A rippled appearance in garments, especially at the seams. [CLEM; p. 32]

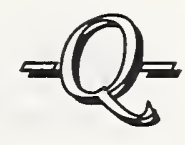

QC

Quality Control

QR

Quick Response

\section{quality}

1. Essential character of something.

[AMFG; p. 521]

2. Superiority, degree, or grade of excellence. [AMFG; p. 521]

3. Perceived level of value. [AMFG; p. 521]

4. Conformance to standards. [AMFG; p. 521]

\section{quality control (QC)}

1. Is the process of maintaining given standards in the product, from the design phase to the consumer's use of the product for a given life with given conditions. [AMHB; p. 562]

2. The effort applied to assure that end products/services meet the intended requirements and achieve customer satisfaction. [AMFG; p. 522]

\section{quality standards}

Minimum specifications and tolerances for materials, production processes, and finished goods; basis of product development decisions and quality control. [AMFG; p. 522]

\section{quick response (QR)}

1. A phrase coined by Roger Milliken, Chairman of Milliken Company, describing the formation of partnerships between vendor and customer, resulting in reduced through-put time by the vendor company. [CLEM; p. 33]

2. Business strategy that compresses cycle time to make ordering and production close to time of sale; increases turnover and reduces investment in inventory. [AMFG; p. 522] 


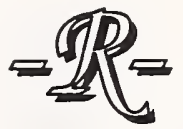

\section{ready-to-wear (RTW)}

Apparel that is mass produced in standard sizes. First ready-to-wear dresses appeared in Paris in 1792. Abbreviated "RTW." Also see "prêt-àporter" and "off-the-peg." [FDF; p. 461]

\section{remnant}

A short length of cloth from the mill.

[CLEM; p. 33]

right side (of fabric)

see "face (of fabric)"

\section{roll line}

see "line, roll"

\section{rolled seam edge}

see "seam edge, rolled"

\section{RTW}

Ready-to-Wear

\section{ruffling}

Is a sewing line whose stitches hold a series of miniature fabric side pleats. It is also sometimes confused with "gathering." [AMHB; p. 182]
SA

seam allowance

S.A.

Seventh Avenue

sample size pattern

see "pattern, sample size"

\section{scissoring}

see "slashing"

\section{seam}

1. A series of stitches that joins two or more plies of material. The term "seaming" (and "stitching") are also used to denote "processing." [AMHB; p. 170]

2. A series of stitches used to join two or more pieces of material together. [AMFG; p. 522]

3. Two edges of fabric, leather, or other material joined by sewing (machine) in a variety of stitches, sometimes incorporating "bias binding," "cording," "piping," or other decorative trimming. [FDF; p. 484]

4. A seam joined by utilizing the short stitch length and small bite of a zigzag pattern.

[FPTS; p. 249]

5. The result of eliminating fabric excess through the manipulation of two or more panels to conform to style line and body contour. [FPTS; p. 9]

6. Result of joining together two or more pieces of fabric by means of stitching or fusing. They are utilitarian, functional, and may be used for decorative purposes. Most are constructed on the "inside" or "wrong side" of the garment.

[FPTS; p. 238]

7. ... with ease; see "seam, eased"

\section{seam, abutted}

A flat seam joining two plies, edge-to-edge, without overlay or seam allowance. [FPTS; p. 239] 


\section{seam allowance}

1. Portion of the muslin or paper pattern extending a determined amount from the seam line to the pattern edge. [FPTS; p. 48]

2. The distance from the fabric edge to the stitching line farthest form the edge. It is planned according to the width needed for the type of seam, seam finish, or garment design. [FPTS; p. 238]

3. The distance from the edge to the needle hole in the seam's stitching line that is most distant from the seam edge. Seam-dimension seam allowance is not equivalent to pattern-drafting seam allowance, although they may sometimes be equal in size. [AMHB; p. 183]

4. ..., extended; That portion of a seam allowance where additional width is provided.

[FPTS; p. 260]

\section{seam binding}

Narrow tape woven on the straight; used at hem of garment to cover raw edge. Also stitched to seams on wrong side to prevent stretching. Sometimes use to bind cut edges of ravelled seams. [FDF; p. 485]

\section{seam, booked}

When the tailored-seam edges have been made with a blindstitch effect. [AMHB; p. 180]

\section{seam, bound}

1. Formed by a narrow strip of fabric encompassing the cut edge of one or more plies. [AMFG; p. 514]

2. Edges of plain seam bound with "bias binding." [FDF; p. 484]

\section{seam, butted}

see "seam, abutted"

\section{seam, butterfly}

Are Ssa- 1 seams whose seam widths have been pressed apart and back onto the fabric holding each seam width. [AMHB; p. 180]

\section{seam, corded piped}

A seam stitched with a corded bias strip, of the same or contrasting fabrics, inserted between the plies to show on the face of the garment. [FPTS; p. 239]

\section{seam, double top-stitched}

A seam which has been pressed open and stitched parallel to and on both sides of the seam line, through garment and seam plies. [FPTS; p. 248]

\section{seam, double welt}

A welt seam with an additional row of topstitching, through all plies, parallel to the original seam-line fold. [FPTS; p. 249]

\section{seam, eased}

Entails the drawing-in or easing of a longer section of a seam line on one ply to fit a corresponding but shorter section of a seam line on the second ply. [FPTS; p. 239]

\section{seam edge, extended}

see "seam allowance, extended"

\section{seam edge, rolled}

An enclosed seam edge where the seam line has been brought slightly to the underside of the garment ply. [FPTS; p. 261]

\section{seam, enclosed}

A construction process that conceals seam allowances between garment plies when they are turned to form a clean finish. [FPTS; p. 259]

\section{seam, exposed}

A seam in which the seam allowances are visible on the inside or outside of the garment. [FPTS; p. 260]

\section{seam finish}

Is applied to the seam allowance (seam edges) to prevent the fabric from raveling, to strengthen the seam, and improve the appearance of the seam. [FPTS; p. 250] 


\section{seam, flat}

Two pieces of fabric abutted together and stitched, usually with a 606 or 607 cover stitch. [AMFG; p. 517]

\section{seam, flat-felled}

The result of enclosing both seam allowances by interlocking opposing folded edges beneath two parallel rows of machine stitching through all plies. [FPTS; p. 240]

\section{seam, French}

1. A trade term for a variation of the Sse-2 seam that is used for some apparel operations. In the Sse-2 seam, the second sewing operation does not enclose the seam edge between the two stitching lines, while in the "French seam," the second operation encloses the seam edge between the two sewing lines. [AMHB; p. 180]

2. Seam first stitched on right-side of garment; trimmed, then stitched on inside of garment to cover the raw edges. [FDF; p. 484]

3. A seam constructed so that a narrow seam is contained within a larger one, producing a clean seam. [FPTS; p. 240]

4. ..., false French; A plain seam made to resemble a French seam by the face-to-face enclosing of the folded seam edges. [FPTS; p. 241]

\section{seam, fused}

A seam formed by the melting process, which joins the line of thermoplastic fabrics. [FPTS; p. 241]

\section{seam, glued}

A lapped seam joined by adhesive.

[FPTS; p. 241]

\section{seam, hairline}

A seam inclosed with closely-stitched rows of machine stitching, zig-zagged or overedged, and trimmed to remove all excess seam allowance. [FPTS; p. 242]

\section{seam heading (SH)}

The distance from the seam's folded edge(s) to the nearest line of needle holes in the seam.

[AMHB; p. 183]

\section{seam, inside curved}

A seam in which the fabric to be stitched or seamed lies on the farther side of an arch, away from the center of the circle of which the arc is a segment. [FPTS; p. 259]

\section{seam, intersecting}

The point where two or more seams meet and cross each other. [FPTS; p. 260]

\section{seam, lap}

Simplest seam used on shoe uppers; made with one edge of leather placed on top of another and topstitched. Also used on gloves. Also called "overlapped seam." [FDF; p. 485]

\section{seam, lapped}

1. A seam joining all thicknesses from the face of the garment and catching the folded edge of the uppermost ply. [FPTS; p. 242]

2. LS-types, called "felled (also flatfell) seams" when one of the seam's edges are folded and held in place by stitching. [AMHB; p. 180]

3. ..., with raw edges; A seam formed by two plies overlaid face-to-back along the seam line, joined by machine or hand stitching, leaving a raw edge exposed on each surface. [FPTS; p. 242]

\section{seam let-out (SLO)}

The distance from the seam edge to the prime line of needle holes in the seam. [AMHB; p. 183]

\section{seam line}

see "line, seam"

\section{seam, "Merrow" \\ see "seam, overedged"}

\section{seam, open-welt}

see "seam, tucked" 


\section{seam, outside curved}

A seam in which the fabric to be stitched or seamed lies on the inner side of an arc, towards the center of the circle of which the arc is a segment. [FPTS; p. 259]

\section{seam, overedged}

A superimposed seam in which all raw edges have been enclosed within the loops of the overedge stitch used to form the seam. Referred to as a "Merrow" seam. [FPTS; p. 243]

\section{seam, overlapped}

see "seam, lap"

\section{seam, padded}

A seam in which a soft strip has been inserted between the seam allowance and garment ply. [FPTS; p. 243]

\section{seam, pinked}

1. Ssa-1 seams whose edges have each been serrated in saw tooth fashion. [AMHB; p. 180]

2. Plain seam pressed open on wrong side and finished by trimming raw edges with pinking shears to make saw-toothed edges that prevent raveling. [FDF; p. 485]

\section{seam, piped}

A seam stitched with a flat straight grain or bias strip, made with the same or contrasting fabric of suitable texture and thickness, inserted between the plies to show on the face of the garment.

[FPTS; p. 244]

\section{seam, plain}

1. Simple seam stitched on wrong side of garment, usually pressed open. Used on a fabric that will not ravel. [FDF; p. 485]

2. A commonly used seam joining two sections of fabric. It may be left as is, or finished with a seam finish. [FPTS; p. 243]

\section{seam, production-eased}

The process of restraining the under ply of a fabric and allowing the upper ply to feed freely while sewing an unbasted seam to compensate for the pull of the feed dog and drag of the presser foot. [FPTS; p. 240]

\section{seam, safety-stitched}

A seam stitched simultaneously with two independent parallel rows of stitches, one securing the seam a specified distance from the edge, and the other overlapping all plies. [FPTS; p. 244]

\section{seam, side}

(v.) To stitch the sides of a garment together, from the sleeve end to the bottom hem end. [CLEM; p. 37]

\section{seam, slot}

A decorative seam in which a backing strip, beneath the folded, faced, or abutted seam line, holds two sections of the garment in place with stitching parallel to the finished seam line. [FPTS; p. 245]

\section{seam, stayed}

A seam on which a reinforcing strip of twill or ribbon tape, bias binding, or self-fabric spanning the opened seam line, is stitched to each seam allowance ply. [FPTS; p. 246]

\section{seam, strapped}

A seam in which the seam allowance on the face or inside of the garment is covered with a stitched-down ribbon or a band made of bias or straight-grain fabric. [FPTS; p. 246]

\section{seam, tailored}

Are butterflied seams whose seam allowance edges have been stitched with an EFa-1 or EFb-1 edge finish. [AMHB; p. 180]

\section{seam, taped}

A seam with twill or ribbon tape, bias binding, net, or a fabric strip, is included in the line of stitching. [FPTS; p. 247] 


\section{seam, tissue-stitched}

A seam in which tissue paper is inserted between the fabric plies, and/or fabric and machine parts, then removed upon completion of the stitching. [FPTS; p. 247]

\section{seam, top-stitched}

1. Term used for the SSq seams and LSq-2 seam when the seam is made in two operations. [AMHB; p. 180]

2. Plain seam pressed open and stitched on either side of seam on right side of garment, or pressed to one side and stitched on reverse side. Also call "double-stitched seam." [FDF; p. 485]

3. A seam which has been pressed to one side and stitched parallel to the seam line, through all plies, from the face of the garment. [FPTS; p. 248]

\section{seam, tucked}

A seam in which the edge of the upper ply, folded along the seam line, forms a tuck when top stitched to the lower ply. [FPTS; p. 248]

\section{seam, welt}

A flat inside seam, graded and pressed to one side; the larger seam allowance being top-stitched to the garment, thereby enclosing the smaller.

[FPTS; p. 249]

\section{seam width, full (FSW)}

The distance equal to stitching seam width plus seam heading(s) and/or seam let-out. It will depend on the type of seam being measured.

[AMHB; p. 183]

\section{seam width, stitching (SW)}

The distance between the two outermost parallel lines of the needle holes on the surface of the seam. [AMHB; p. 183]

\section{seam, zigzagged}

A seam joined by utilizing the short stitch length and small bite of a zigzag pattern.

[FPTS; p. 249]

\section{seamstress \\ see "dressmaker" \\ selvage}

1. Is the finished edge in woven fabrics that runs parallel to the warp. [AMHB; p. 35]

2. The finished edge on either side of a bolt of cloth that prevents fraying and raveling. [CLEM; p. 35]

3. Term used since 14th century for narrow, tightly woven band on either edge of fabric and parallel to the warp that prevents fabric from raveling. Originally called "self-edge." Also spelled "selvedge," and called "list" and "listing." [FDF; p. 486]

4. The narrow, firmly woven finished edge on both lengthgrain sides of a woven fabric. Also spelled "selvedge." [FPTS; p. 70]

5. tight ...; A selvage whose length is shorter than the fabric length in the center of the fabric width when the fabric is placed between two parallel lines that are vertical to the warp; difficult to spread and cut cloth with "tight selvages" because the ripples distort the precision of the cutting. [AMHB; p. 35]

\section{separates}

Product line made up of blouses, skirts, slacks, and so on, whereby each category is marketed individually. [AMFG; p. 522]

\section{serger}

A machine that produces an overedge stitch. It is used primarily as a cover stitch for raw edges. [CLEM; p. 36]

\section{set}

1. (n.) One of the standards of fit, and is the absence of wrinkles in a garment as it covers the body. Because of its dependence on posture and body configuration, as well as the other four standards of fit, is probably the lease readily observable in all portions of a modeled garment. [GTAM; p. 120]

2. (v.) To affix, i.e., to attach physically, e.g. a pocket to a piece of apparel material. [WEB 1; p. 1060, 9b] 


\section{Apparel Manufacturing Glossary for Application Protocol Development}

\section{Seventh Avenue (S.A.)}

Nickname for garment district of New York City, roughly from 34th to 40th Street, and from the Avenue of the Americas (6th Ave.) to 9th Avenue, where much of the American "ready-to-wear" is produced. [FDF; p. 487]

sew

To join together by stitches. [FDF; p. 487]

\section{sewing}

The process of making stitching or seams. [AMHB; p. 170]

\section{sewing machine}

Machine for stitching invented in late 18th century and patented by Thimonnier in France in 1830. Improved on and patented by several others, of whom the most widely known was I.M. Singer in mid-19th century. It was responsible for rapid growth of "ready-to-wear" garment industry. [FDF; p. 487]

\section{sewing position}

1. lapped ... ; One where only the seam areas contact or face each other during the sewing position. [AMHB; p. 180]

2. superposed ... ; That position in which the opposing seam width area surfaces and the other fabric area surfaces (bulk of the fabric) contact each other or face each other throughout their areas when the stitch is formed. [AMHB; p. 180]

\section{$\mathrm{SH}$}

seam heading

\section{shade}

1. Color term for hues with black added to darken. For example, navy blue is correctly called a "shade of blue," whereas light blue with white added, is called a "tint of blue." [FDF; p. 487]

2. Sheer scarf of lace, net, or gauze worn from latter half of 18 th to early 19th century by women over the bosom of a low-necked bodice.

[FDF; p. 487]

3. Piece of knitted or woven fabric worn by women in 1880s, usually attached to a hatband and arranged to fall over the back of the head and neck to prevent sunburn. [FDF; p. 487]

\section{shading}

1. The process of marking and ticketing with successive numbers a cut stack of superimposed (fabric) plies. [AMHB; p. 145]

2 . The process of marking, or ticketing, cut components for shade matching precision and sequence identification with respect to cut components sequence in the spread. [AMHB; p. 120]

3 . The process of measuring or identifying a range of color that "matches." [AMFG; p. 522]

4. ... in a bolt of fabric; The difference in color values that exists within the bolt. [AMHB; p. 39]

5. end-to-end ... ; Changes in (color) shade throughout the length (of the bolt). Is often an imperceptible phenomena. The change in color value, hue, or intensity, is so slight from yard to yard, that the differences are practically imperceptible until one end of the bolt is matched against the other end.

[AMHB; p. 39]

6. side-to-side ... ; Refers to a change in (color) shade from selvage to selvage. Not as prevalent as end-to-end shading imperfection. [AMHB; p. 39]

\section{shearing}

1. Process used on furs to cut hairs to same length to give them a velvety appearance.

[FDF; p. 490]

2. Textile process of clipping nap of fabric to desired length. [FDF; p. 490] 


\section{sheer}

Term applied to any fabric which is fine and transparent or semi-transparent. Especially used as adjective in describing texture of women's hose and pantyhose. [FDF; p. 490]

\section{shirring}

1. (n.) Is a series of parallel corrugations formed by two or more parallel gather sewing lines. [AMHB; p. 182]

2. Three or more rows of gathers made by small running stitches in parallel lines to produce fullness at tops of gloves, skirts, sleeves, and swimsuits. Also called "gauging." [FDF; p. 490]

3. May be made by using a large stitch on the sewing machine and then pulling the bobbin thread to form gathers. [FDF; p. 490]

4. May be made on sewing machine by using elastic thread on the bobbin. [FDF; p. 490]

5. (v.) The control of predetermined fullness drawn up to correspond to a smaller adjoining seamline or specified body measurement. [FPTS; p. 10]

\section{silhouette}

1. Contour or outline of ensemble as shown in solid black on a white background. Similar to a black shadow cast on a white wall. Formerly a term widely used to indicate trend in length and general outline for the coming seasons. [FDF; p. 508]

2. apparel ...; see "apparel silhouette"

3. style ...; see "style silhouette"

\section{size}

Specifies the fitting specifications of a garment, for example men's trousers are specified by the waist and inseam measurement, as 32/32 (inches) [no standard equivalent in metric, at present, exits]. [GIT2; p. 7]

\section{size, base}

The original pattern from which the other sizes are derived. Also referred to as "model size." It is the size in which garment samples are also tested and is in the approximate middle of the size range. [GTAM; p. 123]

\section{size designation}

An arbitrary title or number for a given compilation of anthropometric measurements which are suitable for anyone whose measurements lie within certain tolerance limits of the size measurements. [AMHB; p. 94]

\section{size range}

The sizes of a style which will be cut and made. [CLEM; p. 37]

\section{size scale}

A break-down denoting how many dozens of each size are to be cut. [CLEM; p. 37]

\section{sizing}

1. A fabric finishing process in which a substance is added to the fabric to give it additional strength, stiffness, smoothness, weight, or hand. [CLEM; p. 37]

2. Measurements of (human) body used as guide for cutting garments to fit a variety of body types. [FDF; p. 514]

3. Non-permanent finishing process applied particularly to cotton fabrics to increase weight, crispness, and luster by means of starch, gelatin, oil, and wax. [FDF; p. 514]

\section{sizing standards}

Basic dimensions and proportions of garments specified by a firm. [AMFG; p. 523]

\section{sizing system}

A range of sizes based on graduation of dimensions for a (human) body type. [AMFG; p. 523] 


\section{slash}

1. (n.) The cut or cuts made on muslin or fabric, from the perimeter towards the style or seam line, while draping on the model form. [FPTS; p. 43]

2. (v.) A cutting, from the free edge to a designated point, in the body of a garment section, or from two designated points within the garment.

[FPTS; p. 308]

3. ... for design detail; A straight cut, from edge to a designated point, in the body of a draped muslin or fabric garment section to create design detail. [FPTS; p. 43]

\section{slash-and-spread}

Part of a process for developing a new design and/or introducing fullness to a design by cutting a traced sloper along predetermined guide lines and opening or spreading apart to a designated measurement. Used as an alternative to or in conjunction with the pivot method to manipulate the sloper. [FPTS; p. 35]

\section{slashing}

A 15 th and 16 th century term for vertical slits in clothing that enable the contrasting lining to be pulled through. Also called "scissoring," "chiquetades," and "creves." [FDF; p. 520]

\section{SLO}

seam let-out

\section{sloper}

1. A pattern that approximates either the anatomical perimeter of the individual, or the perimeter of a basic style for the individual. "Slopers" are often called "foundation patterns" because they are used as the basis for developing groups of designs. [AMHB; p. 55]

2. Basic pattern for a garment section, without style lines or seam allowances developed from "model form" (or "dummy"), live model, specific measurements, or manufacturer's specifications. Used to develop original patterns and create new designs. Also called "standard pattern," "foundation pattern," "block pattern," or "master pattern." [FDF; p. 528]
3. A pattern of a garment component, without style lines or seam allowances, developed from specific measurements of a given size, model forms, live models, or manufacturer's specifications. Also called "foundation" (pattern), "master," "block" (pattern), "standard pattern," or "basic pattern."

[FPTS; p. 25, 35]

4. The most popular term used to describe the basic waist, skirt, and sleeve from which all designs are developed. Are developed usually without seams and hems, but when used as patterns, seam and hem allowances must be added. Also called "master patterns," "block patterns," or " foundation patterns." [KOPP; p. 1]

5. The terms "basic block," "sloper," and "master pattern" may refer to the same thing.

[AMFG; p. 130]

\section{sloping}

The process of re-spreading a stack of cut components for pattern chopping. [AMHB; p. 120]

\section{smocking}

1. Decorative needlework used to hold gathered cloth together. The stitches catch alternate folds in elaborate honeycombed designs. [FDF; p. 529]

2. hand ...; Drawing a predetermined fullness into a specific amount by alternately stitching together parallel, uniform folds at regular intervals.

[FPTS; p. 12]

3. machine ...; Drawing a predetermined fullness into a specific amount by means of elastic shirring with an additional overlay pattern of decorative stitches applied to the face of the fabric. [FPTS; p. 12]

\section{specification sheets}

Detail the fabric choices, component materials, colors, widths, style numbers, vendors, and prices. Used by purchasing, costing, and other departments which work simultaneously with the pattern and sample-making departments. [GTAM; p. 88] 


\section{specifications}

The body measurements (of a person), and are stated as circumference measurements (frequently called "girth"), vertical measurements, width, and length. Also called "specs." [GTAM; p. 124]

\section{specs}

1. garment ...; Details that must be established relating to esthetics - the dimensions of silhouette, drape, hand, color (hue, value, intensity, pattern), and surface interest (line balance, depth perception, nap, cover factor). Sometimes a garment sketch with accompanying swatches of fabric are used as the esthetic standard. This in itself is an incomplete standard. The garment sketch and its fabric swatches should have a list of written specs concerning style, detail, and fit. These details (specs) should be stated with minimum words and numbers of units of measurements with plus-or-minus tolerance limits apropos the esthetic features that control quality standard. This should include measurements with tolerance limits regarding fit of the garment. [AMHB; p. 562]

2. soft ...; Specifications that are developed tentatively, and then reaffirmed after sample approval. [GTAM; p. 94]

\section{splice}

1. interlock ...; Refers to a section where opposing ends of successive patterns in the spreading marker interlock instead of meeting at a common vertical line across the width. [AMHB; p. 126]

2. spread ...; There are two types of, the straight-line splice and the interlock splice, which see. [AMHB; p. 125]

3. straight-line ...; Refers to a vertical line, across the width of the spreading and cutting marker, on which the ends of pattern sections abut on both sides of the line. [AMHB; p. 125]

\section{spread}

1. (n.) Superimposed layers of fabric for cutting. [AMFG; p. 523]

2. (n.) The total number of fabric plies, one over the other, in a one-way or fold-back direction, for a particular cutting. Also referred to as "lay," or "layup." [FPTS; p. 104]
3. centered ...; One in which the plies are spread with the longitudinal centers superposed in a vertical line. In a perfect quality spread of this type, both side edges of every ply are equidistant from the lengthwise center of the spread. [AMHB; p. 121]

4. design-one-way ...; Apply only to those fabrics having a design which is asymmetrical with respect to either the length or width direction. [AMHB; p. 121]

5. face-down ...; One where all plies have the "right side" facing toward the table surface.

[AMHB; p. 121]

6. face-to-face ...; One in which all odd-numbered plies face up and all even-numbered plies face down. [AMHB; p. 121]

7. face-up ...; One where all plies are spread with the "right side" of the material facing away from the cutting table surface. [AMHB; p. 121]

8. one-way ...; Both "face up" and "face down" spreads are referred to as this, as they both face "one way." [AMHB; p. 121]

9. stepped ...; Plies of fabric of various lengths that are spread at different heights. [AMFG; p. 523]

10. straight-edge ...; Has all the ply edges on one side of the spread superposed perfectly in a vertical line. [AMHB; p. 121]

\section{spread splice}

see "splice; 2. spread ..."

\section{spreader}

1. Machine used to create a spread. [AMFG; p. 523]

2. A type of spreading machine, classified as (a) stationary spreader - portable or fixed; or (b) traveling spreaders - manual, semi-automatic, or automatic. Stationary spreaders remain in one position on the table during the spreading process; traveling spreaders traverse the length of the spread during the spreading process. [AMHB; p. 123] 


\section{spreading}

1. The process of superposing plies of materials on a table in a manner which permits these plies to be cut simultaneously into product components acceptable for further processing. [AMHB; p. 120]

2. The laying down of many layers of fabric, each on top of the preceding one, into a stack, by one of several methods and machines. [GTAM; p. 155]

3. Process of superimposing predetermined lengths of fabric on a spreading table, cutting table, or specially designed surface, in preparation for cutting. [AMFG; p. 523]

4. ... of goods; The process of superimposing a predetermined number of fabric plies on the cutting table either by hand or manually or by an electrically operated fabric spreading machine. [FPTS; p. 105]

\section{spreading allowance}

An extra amount of fabric allowed above the length and width of the marker. [CLEM; p. 38]

\section{spreading mode}

Manner in which fabric plies are laid out for cutting: face-to-face $(\mathrm{F} / \mathrm{F})$; all plies facing one way $(\mathrm{F} / \mathrm{O} / \mathrm{W})$; nap-up-and-down (N/U/D); and nap-one-way (N/O/W). [CLEM; p. 39]

\section{Standard for the Exchange of Product Model Data (STEP)}

A series of new ISO standards, in the series 10303-X, for representing the physical and functional characteristics of a product throughout its life cycle.

\section{stayed seam}

see "seam, stayed"

\section{STEP}

Standard for the Exchange of Product Model Data

\section{stitch}

1. A loop structure of threads. See Federal Standard No. 751A, which "establishes, defines and illustrates the requirements" for these. [AMHB; p. 170]
2. A formation of thread for the purpose of making a seam. [AMFG; p. 523]

3. One complete motion of a threaded needle or other implement, e.g., a knitting needle or crochet hook, which, when used in a series, results in decorative or utilitarian work, such as sewing, embroidering, knitting, crocheting, or tatting. May be made by hand or machine with thread, yarn, embroidery floss, string, straw fiber, or other material.

[FDF; p. 547]

\section{stitch, cover}

see "coverstitch"

\section{stitch, lock}

Machine stitch done with one thread coming across the top of the machine around the tension and through the needle. Other thread comes from a bobbin on the underside of the machine. [FDF; p. 548]

\section{stitch, overedge}

A stitch whose thread encompasses the cut edge of the fabric piece. The machine trims fabric as overedge stitches are formed. [CLEM; p. 28]

\section{stitching}

1. A series of stitches. If it joins two or more plies of material, it is called a seam. Is also used to denote "processing." [AMHB; p. 170]

2. A series of stitches whose function is only to ornament or encompass an edge of fabric ply. [AMHB; p. 170]

3. A series of stitches used to finish the edge, or decorative stitch on a single ply of material. [AMFG; p. 523]

\section{stitching seam width}

see "seam width, stitching"

\section{straight-of-goods \\ see "lengthgrain"}

\section{straightening}

The cutting of a straight crossgrain across the fabric and from selvage to selvage along the woven crossgrain. [FPTS; p. 70] 


\section{style}

1. In apparel design, is based on eye and tactile appeal. [AMHB; p. 54]

2. The characteristic or distinctive appearance of an item. [CLEM; p. 40]

3. (n.) Fashion term for an individual and distinctive type of dress, coat, blouse, or other item of apparel or accessory. [FDF; p. 553]

4. (v.) style, or styling; Term used by manufacturer when making or selecting the specific types of apparel for seasonal collections, e.g., as in "to ... a line (of clothes)." [FDF; p. 553]

5. Having a certain flair which is specific and individualistic, as in "to have ... ." [FDF; p. 553]

6. The essential characteristic of a garment with regard to silhouette, design feature, proportion, color, and fabric. [FPTS; p. 1]

7. A description of the garment for manufacturing; each garment style is developed for a particular customer. [GIT2; p. 1]

8. The collection of all garments produced by a single manufacturer which look exactly alike. [GTAM; p. 8]

\section{style master}

A complete sequential list of operations involved in assembling a garment component or style. [CLEM; p. 40]

\section{style sense}

The function of the pattern with respect to (1) height, (2) girth, and (3) spirit. Style sense can be transmitted by either: (1) the angular balance in converging or parallel seam lines; (2) the proportions in an area encompassed by seam lines; (3) the ratio between two or more adjacent areas; (4) the ratio between the linear dimensions of converging or parallel seam lines; or (5) any integration of two or more of the first four relationships. [AMHB; p. 94]

\section{style silhouette}

Refers to the geometric perimeter of the (apparel) product. [AMHB; p. 54]

\section{styled block}

see "block, styled" and "pattern, first"

\section{stylist}

(A person who) sets a trend. [AMHB; p. 55]

\section{SW}

stitching seam width

\section{sweep-of-the-hem}

1. A term used in conjunction with the measurement of a hem edge of a garment. [FPTS; p. 49]

2. Circumference at the bottom of a garment [GTAM; p. 116] 


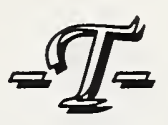

\section{tack}

1. To sew together lightly with invisible stitches, or to join by sewing loosely at just one point.

[FDF; p. 567]

2. back-...(s); see "back-tack(s)"

3. pin ... ; see "pin $\operatorname{tack}(s)$ "

\section{tacking}

Is a stitching sequence which: (1) prevents a stitch chain (in a seam or otherwise) from opening; and (2) holds two pieces of material (cloth, braid, tape, elastic braid, buttons, etc.) intact at one point or small area, under $1 / 2$ " in length. There are two structural types of tacks, back-tacks and pin tacks, which see. [AMHB; p. 293]

\section{tailor}

1. (n.) Person who makes either men's or women's clothes, mends clothing, or does alterations. [FDF; p. 568]

2. (v.) To fit clothing for one individual. [FDF; p. 568]

3. (v.) To fashion a garment. [FDF; p. 568]

4. (v.) To alter a ready-made military uniform for a better fit. [FDF; p. 568]

\section{tailor basting}

see "basting, diagonal"

\section{tailor-made}

1. Garment made specifically for one individual by a tailor - customer's measurements are taken and several fittings are necessary. Also called "custommade" or "custom-tailored." [FDF; p. 568]

2. In the late 19th century, a woman's costume for morning or country wear, usually a suit consisting of a jacket and skirt made by a tailor rather than a dressmaker. [FDF; p. 568]

see also "made-to-measure"

\section{tailored}

Fashion term used to indicate that an item of apparel is relatively plain without decoration, and depends on the line and fit of the item for style. [FDF; p. 568]

\section{tailoring}

Process of cutting, fitting, and finishing a garment to conform to the body by means of darts, lining, hems, and pressing, e.g., a man's suit or coat, or a woman's suit, slacks, or shirt with simple clear lines - no fancy details. [FDF; p. 568]

\section{taped seam}

see "seam, taped"

\section{ticketing}

see "shading"

\section{tissue-stitched seam}

see "seam, tissue-stitched"

\section{toile (twal)}

1. French term for muslin pattern for a garment. [FDF; p. 580]

2. Lace-makers term for pattern of lace, as distinguished from the background. Derived from French, meaning "cloth." [FDF; p. 580]

\section{tolerance}

Allowed variation from a specified minimum value. [CLEM; p. 42]

\section{top-stitched seam}

see "seam, top-stitched" 


\section{TQM (total quality management)}

Total commitment from top to bottom (in a business) to the improvement of the quality of a product. [CLEM; p. 42]

\section{tracing}

The process of transferring pattern lines, using a tracing wheel, onto another sheet (or sheets) of paper or to the opposite side of a folded sheet of paper. Folded draft is opened or sheets are separated and traced lines are pencilled in with the proper tools. [KOPP; p. 3]

\section{tracings}

see "markings"

\section{trim}

1. Materials used to ornament or enhance garments. [AMFG; p. 524]

2. Is an all-inclusive term. In its broadest sense, it includes everything that makes up the garment, except the shell fabric. [GTAM; p. 51]

see also "accessories" and "findings"

\section{trimmings}

Components such as ribbons, laces, "ric rac," lalso spelled "rickrack," or "ricrac,": a flat braid woven to form zigzags [WEB1; p. 996]), bindings, cording, and any other decorative items. [GTAM; p. 51]

\section{true bias}

see "bias, true"

\section{trueing}

1. The process of establishing a corrected seam or style line by blending markings, dots, and/or crossmarks made during pattern development. Includes blending lines. [FPTS; p. 45, 50]

2. The process of connecting all points on a pattern and checking for accuracy of measurements, dartlines, seamlines, crossmarks, shape of seamlines, etc. [KOPP; p. 3]

\section{tuck}

Narrow pleat in fabric of even width, usually stitched in place and used for decorative effects on blouses, shirts, and dresses, particularly children's and babies' dresses. [FDF; p. 587]

\section{tuck, dart \\ see "dart tuck"}

\section{tuck, pin}

(v.) The take-up of excess fabric by means of evenly spaced parallel folds, $1 / 8$ inch $(3.175 \mathrm{~mm})$ or less, and stitched to be released a designated length from the pattern edge or area to be fitted. [FPTS; p. 13]

\section{tuck, released}

The take-up of excess fabric by means of evenly spaced parallel folds, $1 / 4$ to $5 / 8$ inch $(6.35$ to $15.875 \mathrm{~mm}$ ) and stitched to be released a designated length from the pattern edge or area to be fitted. [FPTS; p. 13]

\section{tucking}

A sewing machine process of which there are two major categories, knife tucking and air tucking. Air tucking is done with a multi-needle machine and creates a ridge effect in the fabric plane. Knife tucking is also called "pleat tucking" and is done with a single-needle machine and has a knife-edge fold. [AMHB; p. 248]

\section{tucks}

Usually arranged in a series and designated by widths, e.g., half-inch, quarter-inch, or "pin tucks." [FDF; p. 588]

\section{tucks, pin}

(n.) Tucks that are only wide enough for a row of stitching. [FDF; p. 588] 


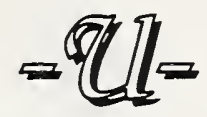

\section{underlay}

Portion of the pattern which constitutes the inside or underside of the design or fold line, or dart pick-up. [FPTS; p. 50]

\section{underlay, dart}

see "dart underlay"

\section{underlining}

A separate ply of shaping fabric of lighter weight and hand than the shell fabric, cut into identical shapes (except shorter), and numbers, as the garment parts. [GTAM; p. 58]

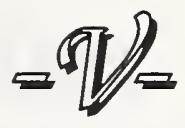

\section{verification-of-pattern}

To ensure that the pattern indeed does conform in size to the specification sheet of finished garment measurements. [GTAM; p. 136]

\section{verifying-the-form}

Testing the model form for the alignment and balance of shoulder-side seam relationship. [FPTS; p. 50] 


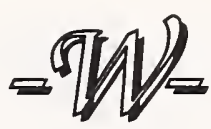

\section{wale}

1. A row of loops parallel to the fabric length. See also "course." [AMHB; p. 31]

2. Textile term for woven ridge in fabric, running vertically in "Bedford cord" and "corduroy"; crosswise in "faille"; and diagonally in twills, like "gabardine" and "whipcord." [FDF; p. 603]

3. Knitting term for row of loops or stitches running warpwise. [FDF; p. 603]

\section{warp}

1. Basic weaving term for yarns in fabric that run parallel to selvage. [FDF; p. 604]

2. (n.) A series of yarns extended lengthwise in a loom and crossed by the woof. [WEB $1 ;$ p. 1320]

3. (v.) To arrange yarns so as to form a warp. [WEB1; p. 1320]

\section{weft}

see "filling"

\section{welt seam}

see "seam, welt"

\section{woof}

A filling thread or yarn in weaving.

[WEB 1; p. 1350]

see also "filling"

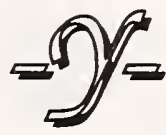

\section{yard goods}

Fabric sold by the yard at retail stores for sewing. Also called "piece goods." [FDF; p. 614] see also "piece goods"

\section{yarn number}

see "count; 4. ... of yarn"

\section{yarn, ply \\ see "ply yarn"}

\section{yoke}

1. Two pieces of fabric attached to the top of the back and the top of the fronts of a shirt which serve as reinforcement for the shoulders and add styling. [CLEM; p. 45]

2. Portion of garment across shoulders in front or back, usually a separate piece seamed across front, and back sometimes lined. In sweaters, yoke is knit in one with body, but nay be different stitch or color pattern. [FDF; p. 615]

3. Fitted top of a skirt connected to waistband to which lower part of skirt may be attached by means of shirring, gores, or pleats. [FDF; p. 615] 


\section{BIBLIOGRAPHY}

\section{[AMFG]}

Apparel Manufacturing: Sewn Product Analysis, by Ruth E. Glock and Grace I. Kunz (Macmillian Pub. Co., New York, 1990)

\section{[AMHB]}

Apparel Manufacturing Handbook (Analysis, Principles, and Practice), 2nd Edt., by J. Solinger, (Bobbin Media Corp., Columbia, SC, 1988)

\section{[CLEM]}

Glossary of Apparel Manufacturing Terminology, by Clemson Apparel Research (Pendleton, SC, 1992)

\section{[FDF]}

Fairchild's Dictionary of Fashion, 2nd Edt., by C.M. Calasibetta (Fairchild Pub., New York, 1988)

\section{[FPTS]}

Fashion Production Terms (Language of Fashion Series), by D.A. Gioello and B. Berke (Fairchild Pub., New York, 1979)

\section{[GIT2]}

Apparel Manufacturing Architecture [Version 1.0], Vol. II: The Information Model, by S. Jayaraman and R. Malhotra, Technical Report SJ-TR-ARCH-9210 (Georgia Inst. of Tech.; Atlanta, GA; October, 1992)

\section{[GTAM]}

Guide to Apparel Manufacturing, by P.B. Hudson (MEDIApparel, Inc., Greensboro, NC, 1988)

\section{[ISO-1]}

Product Data Representation And Exchange, Part 1: Overview and Fundamental Principles, ISO IS 10303-1 (U.S. Product Data Association, Fairfax, VA; ph:(703) 698-9606; 15 Dec 1994)

\section{[KOPP]}

How to Draft Basic Patterns, 3rd Edt., by E. Kopp, V. Rolfo, et. al. (Fairchild Pub., New York, 1984)

\section{[WEB1]}

Webster's New Collegiate Dictionary, (G. \& C. Merriam Co., Springfield, MA, 1977) 

